\title{
Production And Characterization of Transportation Fuels From Domestic Plastic Wastes And Mixed Virgin Plastics By Low- Cost Catalytic Pyrolysis
}

\author{
Praveen Kumar Ghodke \\ NITC: National Institute of Technology Calicut \\ Krishna Moorthy \\ UPES: University of Petroleum and Energy Studies \\ Amit Kumar Sharma ( $\sim$ amit.orgchemistry@gmail.com ) \\ University of Petroleum and Energy Studies \\ Wei-Hsin Chen \\ National Cheng Kung University
}

\section{Research Article}

Keywords: Domestic plastic waste, Pyrolysis, TGA, GC-MS, Alternate fuel

Posted Date: August 13th, 2021

DOI: https://doi.org/10.21203/rs.3.rs-664528/v1

License: (c) (i) This work is licensed under a Creative Commons Attribution 4.0 International License. Read Full License 


\section{Abstract}

With increasing population, modernization, and industrialization, plastics usage is growing daily and results in vast plastic waste. Recycling these plastic wastes to hydrocarbon fuels is challenging due to their different chemical structures, long-chain polymeric compositions, and decomposition/thermal behavior. In the present manuscript, the pyrolysis of domestic plastic waste was carried out at $473-973 \mathrm{~K}$ in a fixed bed tubular reactor and compared with individual virgin plastics, i.e. HDPE (High-density polyethylene), LDPE (Low-density polyethylene), PP (Polypropylene), and their mixture of (virgin mixed plastic). The experiments were also performed using a low-cost catalyst (mineral clay) to maximize hydrocarbon fuels. At identified optimum operating conditions, the domestic plastic waste and mixed virgin plastics yielded $73.1 \mathrm{wt} \%$ and $81.6 \mathrm{wt} \%$ liquid hydrocarbons along with $16.9 \mathrm{wt} \%$ and $25.5 \mathrm{wt}$ \% pyrolysis gas, respectively. The composition of liquid fuels was analyzed using FTIR and GC-MS in detail, revealing a wide variety of hydrocarbons disbursement in the range of C8-C20. In addition, fuel properties of liquid fuels such as viscosity, density, fire and flash point, pour point, and calorific value was analyzed according to ASTM methods and found to be satisfactory. Based on chemical composition and fuel properties, liquid fuels derived from domestic plastic wastes showed $78.05 \%$, and $61.86 \%$ similarity with diesel, and jet fuels respectively. Noncondensable gases, which mainly consist of ethane and propene with minor amounts of hydrogen and methane, have been identified to be ideal for spark-ignition engine (SI) engines. This study offers a unique technique for converting waste plastics into transportation jet fuel using an affordable catalyst.

\section{Introduction}

Plastics are durable and non-biodegradable. The demand for plastic has increased due to its attractive applications like packaging, utensils, and other industrial use. According to CPCB latest report, the generation of plastic waste in India for 2018-2019 was around 9.46 million tonnes per year (Rafey and Siddiqui 2021). Therefore, the disposal of plastic debris has become a critical challenge nowadays. Depending on local restrictions, landfilling and open dumping, ocean dumping, incineration, and recycling are the common approaches used to dispose of plastics (Damodharan et al. 2018; Tulashie et al. 2019). However, these methods result in several economic and environmental concerns. (Bharathy et al. 2019; Dobó et al. 2019; Chandran et al. 2020). In recent years, the investigation has switched on the recovery of energy from plastic wastes, which solves plastic waste management and generates energy as a value-added product. As a result, a simple, effective, and low-cost technique for resolving plastic pollution and converting it into useful energy products is required. Thermochemical conversion of mixed plastic waste (MPW) to fuel is a potential technique for meeting energy demands in the industrial, transportation, and agriculture sectors and solid waste management. There have been numerous studies on the pyrolysis of particular types/unmixed plastic resources (Honus et al. 2016; Miandad et al. 2017a; Park et al. 2019; Thahir et al. 2019; Jahnavi et al. 2020). However, municipal/domestic plastic waste primarily consists of low-density polyethylene (LDPE), highdensity polyethylene (HDPE), polyethylene terephthalate (PET), polypropylene (PP), polystyrene (PS), and poly (vinyl chloride) (PVC) (Achilias et al. 2007; Adrados et al. 2012; Quesada et al. 2019). Hence, mixed-waste separation and material variability are major obstacles to the wider use of the technique. Till now, no commercial plants are available to convert the domestic/municipal plastic waste into fuel due to its thermal decomposition behavior which makes it challenging to convert usable fuel in a single reactor. The information on plastic waste conversion's technological aspects is scanty and needs to investigate deeply to utilize the plastic waste to fuel.

Pyrolysis is one of the important thermochemical conversion technologies for the transformation of plastic waste into valuable products like liquid fuel, gas fuel, and carbon black (Al-Salem et al. 2009; Artetxe et al. 2010; Kumar et al. 2011; Părpăriţă et al. 2014). It is an endothermic response where volatile matter of input plastic waste decomposes to produce condensable vapors, non-condensable gases and solid pyro-char (fixed carbon and inorganic compounds (glass, metals, ash, etc.). The inorganic compounds from pyrolysis remain unchanged which can be reused in chemical modification/recovery, laying transportation roads or additives for other plastics, etc., (Dai et al. 2017; Rajamohan and Kasimani 2018; Dobó et al. 2019). 
There are few considerable numbers of studies that have been reported on the production and utilization of plastic waste of a particular kind. For example, Hazrat 2014., performed the pyrolysis of high-density polyolefin in the temperature range 373$753 \mathrm{~K}$ and observed the liquid product contain hydrocarbon waxes, gums, and coke along with light oils (Hazrat et al. 2014; Sharuddin et al. 2017; Breyer et al. 2017; Miandad et al. 2017b). The batch process of virgin plastic (PE, PP, PS, and PET) to crude liquid fuel was studied by T.Williams and Slaney, 2007 in Parr mini autoclave at $773 \mathrm{~K}$ and found that the yields of 90$95 \%, 5-10 \%$ and $1 \%$ of liquids, gases and solid residue respectively (T.Williams and Slaney 2007). Shah et al., 2010, has conducted low-temperature pyrolysis of used plastic in a batch reactor. The feedstock used was a mixture of LDPE and PP with $3 \mathrm{~mm}$ in length. The common yield of the liquid hydrocarbon fuel from pyrolysis of plastic waste results in $48.6 \mathrm{wt} \%$ at $548 \mathrm{~K}$ with the non-catalytic pyrolysis technique (Shah et al. 2010). Siddiqui and Redhwi, 2009, studied thermal plus catalytic pyrolysis of PS with LDPE, HDPE, PP, PET plastics in a $25 \mathrm{~cm} 3$ batch stainless steel microreactor at approximately $705 \mathrm{~K}$ under 5.5-6.0 MPa of N2 gas pressure for $1 \mathrm{~h}$. Three reactions of each plastic with PS were conducted in the ratio of 1:1, 1:2 and 1:3, ratio and 1:1 has the maximum yield of liquid hydrocarbon fuel (Siddiqui and Redhwi 2009; Ahmad et al. 2020). This is in comparison with Abbas and Shubar, 2008, who had conducted the experiments in a batch autoclave reactor, where feed was HDPE plastic and observed the utmost yield of $70 \mathrm{wt} \%$ at $753 \mathrm{~K}$ in a time of $20 \mathrm{~min}$ (Abbas and Shubar 2008). Demirbas, 2004 , studied the pyrolysis process in a thermogravimetric analyzer of used plastic of PS, PE and PP and observed that degradation finished between temperatures of 447-497 K (Demirbas 2004). Miskolczi et al., 2004, has tested the PP \& PE plastics for the production of hydrocarbon fuels through thermal cracking in horizontal tubular reactors at $798 \mathrm{~K}$ and found

yields are dependent on the composition of plastic feed and residence time (Miskolczi et al. 2004). These studied showed that pyrolysis is a best techniques to convert plastic waste to fuel. However, the use of catalysts leads to the up-gradation of volatiles generated during the pyrolysis process and plays a significant role in the selectivity of the target product or desired product such as diesel, gasoline, or jet fuel. It is expected to rise demand for aviation fuels, especially high-density jet fuels, up to $27 \%$ compared with gasoline in the coming years (Zhang et al. 2019). Jet fuel comprises of C8 to C16 hydrocarbons including aliphatic alkanes (paraffin) and cycloalkanes (naphthenes) with some aromatics compounds (Zhang et al. 2017, 2019). Recently some researchers showed that plastic wastes may be good source of jet fuel range hydrocarbons (Zhang et al. 2017, [CSL STYLE ERROR: reference with no printed form.], 2019; Huo et al. 2020). They have used various type of catalyst like MgO, activated carbon, ZSM-5 catalyst, mercial NiMo/Al2O3/P catalyst(Zhang et al. 2017, [CSL STYLE ERROR: reference with no printed form.]; Huo et al. 2020; Tomasek et al. 2020). However, this study investigates effect of low cost catalyst i.e. mineral clays on the quality of liquid hydrocarbons from mixed plastic waste and mixed virgin plastic

In contest to above, pyrolysis of domestic plastic waste and mixed virgin plastic was carried out to get the liquid product having diesel or jet fuel hydrocarbons range in batch stainless steel tubular reactor. Very few studies available on the effect of operating temperatures to convert virgin/domestic plastic into usable alternate fuels (Rajendran et al. 2020). Hence, this study aims the pyrolysis of domestic plastic waste, HDPE, LDPE, PP and mixed virgin plastic (MVP) at different temperature for maximum hydrocarbon yield. The main objective of the study was to identify the decomposition behavior and decomposition temperature of domestic plastic waste, virgin plastics, and mixed virgin plastic. In addition, reaction products were analyzed and characterized to see their feasibility as an alternative to gasoline, diesel, or jet fuel.

\section{Materials And Methods}

\subsection{Materials}

Virgin polypropylene (PP), high-density polyethylene HDPE), low-density polyethylene (LDPE), and Polyethylene terephthalate (PET) having $3 \mathrm{~mm}$ nominal granule size were obtained from Aldrich, India. Virgin mixed plastic was prepared by considering domestic plastic waste (PP 27wt\%, LDPE 60wt\%, HDPE 10wt\%, and PET 3wt\%) composition. Domestic plastic waste was collected from the University of Petroleum and Energy Studies (UPES), Dehradun campus, India, dustbin containers. It was observed that domestic plastic waste contains, on average ( 50-60 wt\% LDPE, 30-35 wt\% PP, 10-12 wt\% HDPE, and 1-3 wt $\%$ PET ). Plastic bottles, polyethylene carry bags, bread packets, Maggi covers \& cups, spoons, plastic files \& folders, pet bottles, and cable covers were among the plastic waste collected, which were shredded into small pieces and sieved to a particle size of $1-3 \mathrm{~cm}$, then cleaned and dried for experimentation and analysis. Chemicals like Benzene (AR, 99\% pure), and 
Aniline (GR, 99.8\%) were obtained from Merck Ltd., India. N-butylamine (AR, 99.8\%) was obtained from s-d Fine-chem Ltd., India.

\subsection{Characterization of feedstock:}

\subsubsection{Proximate and Ultimate analysis:}

Proximate analysis was carried out to evaluate the combustion properties, including moisture content, volatile matter, fixed carbon, and ash. A higher heating value was determined using a bomb calorimeter. Ultimate analysis was carried out using a CHNS analyzer (varioMICRO CHNS) to evaluate the carbon, hydrogen, nitrogen, and sulfur elements present in the domestic plastic waste, mixed virgin plastics, and individual virgin plastics (LDPE, HDPE, and PP) along with hydrocarbon fuels. Properties of LDPE, HDPE, PP, mixed virgin plastic (MVP), and domestic plastic waste (DPW) are depicted in Table 1.

Table 1

Characteristic properties of different plastic feedstocks (dry basis)

\begin{tabular}{|llllll|}
\hline & \multicolumn{3}{l}{ Virgin plastic } & \multicolumn{3}{c|}{ Mixed virgin plastic } & Domestic plastic waste \\
\cline { 2 - 5 } & PP & HDPE & LDPE & \\
\hline Volatile matter (wt\%) & 99.9 & 97.7 & 98.78 & 93.45 & 98.72 \\
\hline Fixed carbon (wt\%) & 0.09 & 2.12 & 1.12 & 5.34 & 1.17 \\
\hline Ash (wt\%) & 0.01 & 0.18 & 0.1 & 1.21 & 0.11 \\
\hline Bulk Density (kg m ${ }^{-3}$ ) & 0.574 & 0.584 & 0.552 & 0.862 & 0.56 \\
\hline Conradson Carbon residue & 0.2 & 0.68 & 0.61 & 1.34 & 0.51 \\
\hline Heating value (MJ kg ${ }^{-1}$ ) & 41.1 & 42.1 & 45.7 & 40.42 & 42.04 \\
\hline Carbon (wt\%) & 83.49 & 85.26 & 85.85 & 84.43 & 84.88 \\
\hline Hydrogen (wt\%) & 16.13 & 14.65 & 14.15 & 12.45 & 14.83 \\
\hline Nitrogen (wt\%) & 0.28 & 0.09 & 0 & 2.71 & 0.26 \\
\hline Sulfur (wt\%) & 0.1 & 0 & 0 & 0.41 & 0.03 \\
\hline H/C ratio & 0.19 & 0.17 & 0.16 & 0.15 & 0.17 \\
\hline
\end{tabular}

It was observed from Table 1 that all plastics feedstock contains high amounts of volatile matter $>97 \%$ and less percent of fixed carbon, which can infer to $97 \%$ conversion, can be achieved. Plastics feedstock measures higher heating values comparable to that of diesel, petrol and natural gas. From the ultimate analysis of plastic (Table 1), it was observed that virgin polypropylene has a high $\mathrm{H} / \mathrm{C}$ ratio, whereas domestic plastic waste has $0.17 \mathrm{H} / \mathrm{C}$ ratio equivalent to HDPE. Lesser the $\mathrm{H} / \mathrm{C}$ ratio, lesser will be the heating value of the feedstock. Plastic bulk density was measured as per ASTM D1895B and results shown that LDPE was lighter in weight compared to all the feedstock chosen for the pyrolysis process.

To identify the coke forming tendency of any fuel, conradson carbon residue (CCR) test was performed in a special distillation column at atmospheric pressure and measured the carbon residue. It was observed from Table 1 that domestic plastic waste have the carbon residue $1.34 \mathrm{wt} \%$ than mixed virgin plastic $(0.51 \mathrm{wt} \%)$ which signifies complex structure of carbon possible from different plastic available in domestic plastic waste. Heating value of plastic feed-stock and liquid hydrocarbon fuels are analysed using a bomb calorimeter as per ASTM D240-17.

\subsubsection{Thermo gravimetric analysis (TGA)}

Mass loss of plastic feedstock was measured using a thermo gravimetric analyzer (SII 6300 EXSTAR) to understand the decomposition of plastic feedstock with time and temperature. Nitrogen was used as inert gas at a flow rate of $150 \mathrm{~mL} \mathrm{~min}^{-1}$ 
over a temperature range of $303 \mathrm{~K}$ to $1173 \mathrm{~K}$. Differential thermo gravimetric analysis was derived and analyzed in further sections. A Uniform sample weight of up to $10 \mathrm{mg}$ was used in all TGA analysis.

\subsection{Experimental set up and and procedure}

The experiment was conducted in a fixed bed reactor under non-isothermal conditions and at inert atmospheric pressure. The main reactor (S1) consists of a cylindrical quartz column of $420 \mathrm{~mm}$ height and an internal diameter of $75 \mathrm{~mm}$; heating zone is at an adequate distance from the inlet to facilitate the preheating of the feed gas. The heating coil maintains the desired temperature of the heating zone connected with the programmable temperature controller. Sample weight of $\sim 100 \mathrm{~g}$ was used for all the experiments. Initially, the reactor was purged with inert gas, i.e., nitrogen, at a flow rate of $500 \mathrm{ml} \mathrm{min}^{-1}$. All the experiments were carried out at required temperatures with an optimum heating rate of $10^{\circ} \mathrm{C}$ min- 1 from room temperature and hold for $30 \mathrm{~min}$ at that particular temperature to ensure the completion of pyrolysis. As the pyrolysis process proceeds, volatiles produce from the plastic waste are passed through three bottle jacketed water-cooling condensers unit ( each bottle $500 \mathrm{ml}$ capacity) to condensed in liquid form. These bottle condenser were connected in series and kept under the temperature conditions of $6^{\circ} \mathrm{C}$ (Figure S1). Non-condensable gases exit through the vent provided where collected in the bladder and perform the qualitative analysis.

Each feedstock was pyrolysed at the temperature range of $473 \mathrm{~K}$ to $973 \mathrm{~K}$ to optimize the best yield of liquid, solid and gaseous products. In addition, MVP and DPW were also pyrolysed in presence of a catalyst (10 wt \%) at same temperature conditions. After the completion of the experiment, residue and condensed liquid were measured and calculated the yields in weight percentage. Each experiment is repeated twice, and average values are shown in the manuscript.

Miniral clay was used as a catalyst. Before using mineral clay as a catalyst, it was characterized for mineral content by X-ray fluorescence (Bruker S4 Poinner make), phase identification of crystalline material by X-ray powder diffraction (Bruker make D8 ADVANCE ECO instrument equipped with SSD160 1-D detector). The acidity of the catalyst was measured using the titration method as per Benesi 1957. The surface area of the catalyst was investigated by physical adsorption/desorption of nitrogen on a solid surface at $-196^{\circ} \mathrm{C}$ (BET 20 method) with autosorb BET apparatus from ASAP 2020 Micromeritics, USA. Catalyst was pretreated (calcinated at $120^{\circ} \mathrm{C}$ ) before subject to any characterization technique.

\subsection{Product analysis:}

The chemical characteristics of solid feedstock and liquid product were analyzed for FTIR to understand the functional group. Perkin Elmer's FTIR spectrometer, a research facility available used to record the IR spectra in the range of $400-4000 \mathrm{~cm}^{-1}$ at a resolution of $4 \mathrm{~cm}^{-1}$ using the standard $\mathrm{KBr}$ (potassium bromide) technique. To identify the chemical composition of liquid hydrocarbons, GC-MS and FTIR analysis were performed. Perkin Elmer`s Gas Chromatography (GC) equipped with DB-5ms capillary column with i.d. $0.25 \mathrm{~mm}$ and length of $30 \mathrm{~m}$ was used to identify the chemical composition, and unknown compounds are matched with standard NIST 11 libraries. Helium was used as carrier gas at a flow rate of $1.5 \mathrm{ml} \mathrm{min}^{-1}$, with a split ratio of 50:1, and $70 \mathrm{eV}$ ionization energy was applied to detect the mass. The GC oven was maintained at an initial temperature of $348 \mathrm{~K}$ for $10 \mathrm{~min}$ and increased to $573 \mathrm{~K}$ at a heating rate of $10 \mathrm{~K} \mathrm{~min}^{-1}$, and held for $25 \mathrm{~min}$ to ensure the elution of all possible high boiling compounds. The non-condensable gases were collected in the balloon and immediately analyzed using gas chromatography (GC) equipped with a thermal conductivity detector (TCD) and flame ionization detector (FID). Hydrogen $\left(\mathrm{H}_{2}\right)$, nitrogen $\left(\mathrm{N}_{2}\right)$, carbon monoxide $(\mathrm{CO})$ and carbon dioxide $\left(\mathrm{CO}_{2}\right)$ gases were separated in a molecular sieve packed column at the injector temperature $393 \mathrm{~K}$ and detector temperature $433 \mathrm{~K}$ isothermally with argon as a carrier gas. Hydrocarbon non-condensable gases from $\mathrm{C} 1$ to $\mathrm{C} 4$ were analyzed in a HayeSep packed column with injector temperature $423 \mathrm{~K}$ and detector temperature $473 \mathrm{~K}$ isothermally. All the physical characteristics were determined as per ASTM standards.

\section{Results And Discussion}

\subsection{Characterization of plastic feedstock}




\subsubsection{Thermo gravimetric analysis (TGA) analysis of plastic waste}

TGA is a standard technique that demonstrates the sample's behavior with respect to time, temperature, and heating rate and helps to get optimum temperature range for plastic polymer degradation. TGA analysis curve of domestic plastic waste and virgin plastics under the conditions of non-isothermal $(10 \mathrm{~K} / \mathrm{min})$ range and from $300 \mathrm{~K}$ to $950 \mathrm{~K}$ temperature are represented in Fig. 2. As shown in Fig. 2, the thermal decomposition of LDPE, HDPE, and PP plastic was almost similar. The decomposition of LDPE was started at $573 \mathrm{~K}$ with an initial mass of $96.24 \mathrm{wt} \%$ and reached up to mass of $3.4 \mathrm{wt} \%$ at $720 \mathrm{~K}$. Similarly, the degradation of HDPE started with mass of $94.20 \%$ at $613 \mathrm{~K}$ and achieved up to $6.57 \%$ at $749 \mathrm{~K}$ (Fig. 2b). The degradation range of HDPE was slightly higher than LDPE which may be due to the reason that HDPE has more branched hydrocarbon bonds than LDPE and signified the stronger intermolecular forces and physical strength. Therefore, it requires more temperature to degrade(Chandran et al. 2020). On the other support, the degradation of PP began at $648 \mathrm{~K}$ with an initial mass of $95.2 \mathrm{wt} \%$ and reached up to $2.6 \mathrm{wt} \%$ at temperature $750 \mathrm{~K}$ (Fig. 2c), indicating single step degradation. The presence of single DTG peak also supports the fact that the degradation of all these three plastic feedstock i.e., LDPE, HDPE, and PP, takes place in a single step. Temperatures at which maximum degradation rate takes place is called peak temperature (Tmax), while the temperature at which maximum degradation began is denoted as onset temperature (To), and temperature at which degradation ended termed as end temperature $(\mathrm{Te})$. The values of these temperatures vary for different source materials. Since the rate of degradation changes as reaction time (temperature) increases, the changes in product distribution of both gas and liquid phases are also to be expected. In this study, Peak temperature Tmax for LDPE, HDPE and PP was $703 \mathrm{~K}, 700 \mathrm{~K}$ and $721 \mathrm{~K}$ respectively while end temperature was $720 \mathrm{~K}, 730 \mathrm{~K}$ and $740 \mathrm{~K}$ respectively. Total mass loss for LDPE, HDPE and PP was of $92.84 \mathrm{wt} \%, 88.63 \% \mathrm{wt} \%$, and $90.9 \mathrm{wt} \%$ corresponding to these temperatures. Therefore, the yield of product distribution varied with these feedstocks. In domestic plastic waste and mixed virgin plastic, Tmax was $740 \mathrm{~K}$ and $744 \mathrm{~K}$, respectively higher than individual plastics. In addition, there were three peaks detected in DTG curve (Fig. $2 d$ and $2 e$ ) which indicates that degradation of domestic plastic waste and mixed virgin plastic is a significant multiple reaction process and therefore, total mass loss occurs in more than two reactions. This is due to the synergistic effect when all three plastic materials degrade together (Singh and Ruj 2016). However, onset temperature (To) for domestic plastic waste and mixed virgin plastic was observed to be $614 \mathrm{~K}$ and $654 \mathrm{~K}$ while end temperature $(\mathrm{Te})$ was $749 \mathrm{~K}$ and $758 \mathrm{~K}$, the mass loss was higher for mixed virgin (92.20\%) compared to domestic plastic waste (89.93\%).

Domestic plastic waste decomposes at a lower temperature as compared to mixed virgin plastics. The main reasons could be due to a change in the structural composition of household plastic waste while molding from virgin plastic into finish products. The addition of binders, fillers, coloring agents, etc., may cause mixed plastic waste to decompose at lower temperatures than unprocessed virgin plastics. Based on To and Te, it can be predicted that the pyrolytic zone for both domestic plastic waste and mixed virgin plastic lies in the range of 600 to $754 \mathrm{~K}$ temperature. These data were found to be similar to other studies carried out by different researchers (Singh and Ruj 2016; Miandad et al. 2017a; Zhang et al. 2019).

\subsubsection{FTIR analysis of plastic feedstock}

FTIR analyses of domestic plastic waste along with virgin plastics are depicted in Fig. 3. Typically, in plastics, large monomers are combined to form polymer compounds. Some polymers contain olefinic composition, and some are supported by oxygen doping. However, domestic plastic waste contains fillers, binders, additives, etc. which can be determined by FTIR spectra with reference to stretching frequencies of the hydrocarbon composition. It can be observed from Fig. 4, the stretching frequencies of $=\mathrm{C}-\mathrm{H},-\mathrm{C}-\mathrm{H}, \mathrm{C}-\mathrm{C}$ were around $2900-3000 \mathrm{~cm}^{-1}$, which refers to the presence of hydrocarbon groups such as alkanes alkenes, and alkynes. This behavior can be attributed to closed and very packed hydrocarbon compounds and long-chain, closely packed hydrocarbons. Wave numbers are slightly shifted above $3000 \mathrm{~cm}^{-1}$. Stretching frequencies of $=\mathrm{C}-\mathrm{H},-\mathrm{C}-\mathrm{H}, \mathrm{C}=\mathrm{C}$, and bending frequencies of $-\mathrm{C}-\mathrm{H}, \mathrm{C}=\mathrm{C}$, and $=\mathrm{C}-\mathrm{H}$ were depicted in spectra according to their ranges. In domestic plastic waste, some oxygen-containing groups are also present in the frequency range of $2600-2900 \mathrm{~cm}^{-1}$. Table 2 shows the detailed summary of the FTIR analysis of domestic plastic waste and mixed virgin plastic. Detailed information about the different 
hydrocarbon's functional groups and their behavior, strength, and mode of vibration such as bending or stretching behavior are given the Table 2 .

Table 2

Summary of functional group analysis of plastic feedstock

\begin{tabular}{|lll|}
\hline Wavelength & Functional Group & Remark \\
\hline $3200-3000 \mathrm{~cm}^{-1}$ & Alkene & $=\mathrm{C}-\mathrm{H}$ stretch, $\mathrm{C}-\mathrm{H}$ stretch, $\mathrm{CH}_{3}, \mathrm{CH}_{2} \& \mathrm{CH}$ (strong) \\
\hline $2962 \mathrm{~cm}^{-1}$ & Alkane & $-\mathrm{C}-\mathrm{H}$ stretch, $\mathrm{CH}_{3}, \mathrm{CH}_{2} \& \mathrm{CH}$ (strong) \\
$1650 \mathrm{~cm}^{-1}$ & Alkene & $\mathrm{C}=\mathrm{C}$ stretch \\
\hline $1458,1377 \mathrm{~cm}^{-1}$ & Alkane, alkene & $-\mathrm{C}-\mathrm{H}$ bending, $\mathrm{C}=\mathrm{C}$ bending. \\
\hline Below $1000 \mathrm{~cm}^{-1}$ & Alkane, alkene & $=\mathrm{C}-\mathrm{H}$ bending and fingerprint region \\
\hline
\end{tabular}

\subsection{Product distribution of pyrolysis reaction with domestic plastic waste, PP, LDPE, HDPE, and mixed virgin plastic:}

The Product distribution of pyrolysis reaction with domestic plastic waste, PP, LDPE, HDPE, and mixed virgin plastic is depicted in Fig. 4. Pyrolysis of these plastics was performed in the temperature range of $573 \mathrm{~K}$ to $973 \mathrm{~K}$ with a constant heating rate of $10 \mathrm{~K} / \mathrm{min}$. Liquid hydrocarbon fuel, non-condensable gases (pyrolysis gases), and solid residue (pyrochar) were the main products of the reaction. The results showed that the yield of gaseous products was increased with the rising of temperature while liquid product yield increased with a specific temperature, and after that, it was found to be decreased with increasing temperature. As shown in Fig. 4a, LDPE's liquid hydrocarbons fuel yield increased from 4.3\% (473 K) to $64.6 \%$ (773 K) due to the devolatilization reactions being supported by higher temperatures. When the temperature increased beyond 773 $\mathrm{K}$, the liquid product yield was reduced from $64.6 \%(773 \mathrm{~K})$ to $30.8 \%(973 \mathrm{~K})$. This may be due to secondary thermal cracking, which results in decomposition of these liquid hydrocarbons into non-condensable hydrocarbons. In addition, higher temperature favors the cracking of the large hydrocarbon molecules into small molecular products (Thahir et al. 2019). Therefore, the yield of gaseous hydrocarbons was found to be increased with increasing temperature. The poor yield of liquid and gaseous hydrocarbons at lower temperatures was due to incomplete reaction.

Figure $4 \mathrm{~b}$ shows the product distribution of HDPE virgin plastic pyrolysis. HDPE liquid hydrocarbons yield was observed maximum (62.2 wt.\%) at $773 \mathrm{~K}$. In contrast, gaseous hydrocarbon was maximum (68.6 wt.\%) at $973 \mathrm{~K}$. The trend of solid, liquid and gaseous hydrocarbon yield was almost similar to LDPE pyrolysis products. However, LDPE produced a higher amount of liquid products compared to HDPE and PP. The results of PP pyrolysis are shown in Fig. 4c and demonstrated that the maximum value of liquid and gaseous hydrocarbons was $63.1 \%$ and $66.8 \%$ at the temperature of $773 \mathrm{~K}$ and $973 \mathrm{~K}$, respectively. At higher temperatures, condensable undergo secondary reactions in which large molecules further break down to smaller molecules, thereby reducing the condensate and increasing the non-condensable gases (Ruiz et al. 2017). Solid residue decreases with increasing temperature and almost produces a fixed amount of $4.2 \mathrm{~g}$ to $1.5 \mathrm{~g}$ at $773 \mathrm{~K}$ onwards. These data also supported by TGA analysis. The liquid hydrocarbons were lesser than LDPE but higher than HDPE.

In addition, to see the combined effect of LDPE, HDPE, and PP pyrolysis, all these three virgin plastics were mixed into a particular ratio, and results were compared with mixed virgin plastic and domestic plastic waste. It was noted that the mixed virgin plastic composition was almost identical to that of domestic plastic garbage collected from university campuses. The pyrolysis results of mixed virgin plastic and domestic plastic waste are shown in Figs. $4 \mathrm{~d}$ and $4 \mathrm{e}$. Pyrolysis of mixed virgin plastic was carried out to identify the fuel quality and compare it with the real-time quality of domestic plastic waste. It was observed that liquid hydrocarbon fuel from HDPE virgin plastic was waxy oil while PP and LDPE virgin plastic pyrolysis resulted in a clear liquid. In the case of mixed virgin plastic, liquid hydrocarbons were again completely in liquid form, which 
may be because waxy oil from HDPE is soluble in other liquid hydrocarbons fuel at room temperature. As illustrated in Fig. 4d, the mixed virgin plastic yielded maximum $68.6 \%$ liquid product at $723 \mathrm{~K}$ temperature, while domestic plastic waste resulted in $64.5 \%$. In addition, the liquid products yield was higher for mixed virgin plastic compared to individual virgin plastic. The reason behind this may be due to the synergetic effect of decomposition of LDPE, HDPE, and PP simultaneously during pyrolysis reaction (Das and Tiwari 2018). On the other hand, gaseous hydrocarbon yield was reached up to $64 \%$ at $973 \mathrm{~K}$.

Domestic plastic waste behaves quite differently in pyrolysis than mixed virgin plastics because it contains a variety of other polymers in traces (1-5\%), as well as coloring agents, additives, and other materials. In the narrow temperature range of $723 \mathrm{~K}$ $-773 \mathrm{~K}$, the highest yield of liquid product was reported to be $60.3 \%$ to $64.5 \%$ (Fig. 4e). However, the maximum yield of liquid and gaseous products was observed lower for domestic plastic waste compared to mixed virgin plastic. This may be due to some polymer binders and coloring agents present in domestic plastic waste (Siddiqui and Redhwi 2009; Das and Tiwari 2018).

\subsubsection{Catalytic pyrolysis of domestic plastic waste and mixed virgin plastic}

Pyrolysis of domestic plastic waste was also carried out using low-cost catalyst mineral clays and compared to mixed virgin plastic to increase product output. Detailed characterization of the catalyst was examined to see mineral compositions and their impact on catalytic reactions. XRF analysis showed that the catalyst has $\mathrm{Si}, \mathrm{Al}, \mathrm{Fe}, \mathrm{Na}, \mathrm{Mg}$ elements in a major quantity while $\mathrm{Ca}, \mathrm{K}, \mathrm{Mn}, \mathrm{Ti}, \mathrm{P}$ as minor elements. Detailed metal oxide composition of the catalyst is represented as a supplementary file S 2. It was observed from XRF analysis that the catalyst has about $48 \%$ oxides of aluminum and $30 \%$ of oxide of silica which supports its acidic nature and catalyzes the cracking reactions of higher hydrocarbons. XRD analysis showed the reflection at $2 \theta$, corresponding to 001 , observed to sharp, well-defined, distinct peak indicating a crystalline nature of the catalyst. The acidity of the catalyst mineral clays was determined using Anthraquinone as an indicator (Yurdakoç et al. 1999) and the acid number (pKa range of strongest sites) of the catalyst $<\otimes 8.1$ and total acidity to pKa 4.0 was approximately 0.05 meq amines/g. FTIR and XRD analysis are showed as supplementary files S3 and S4. FTIR analysis revealed that the catalyst mainly contains the inorganic hydroxyl group $\mathrm{OH}$ stretching at bands $3452 \mathrm{~cm}^{-1}$ and $\mathrm{OH}$ deformation bands at $1000 \mathrm{~cm}^{-1}$. Silica stretch was observed at $563 \mathrm{~cm}-1$ and deformation band at $1000 \mathrm{~cm}^{-1}$, peak at $1000 \mathrm{~cm}^{-1}$ is wide.

Catalytic pyrolysis reaction showed that the yield of liquid products from domestic plastic waste was improved from $64.5 \%$ to $73.1 \%$ at $773 \mathrm{~K}$ while mixed virgin plastic resulted in improved liquid product from $68.6 \%$ to $81.6 \%$ (Fig. 5). At high temperatures, cracking was so effective because of which condensable gases were further cracked to non-condensable gases. In addition, the improvement in the yield of liquid products was observed higher for mixed virgin plastics (13\%) compared to domestic waste plastic (8.6\%). However, the pattern of liquid and gaseous fuel production was similar to the reaction performed without catalyst. This may be due to the fact that there are some impurities in waste plastic in the form of coloring agent, binders etc. which act as poison for acidic catalyst and led to the deactivation of catalyst in the case of conversion of waste polymers (Huo et al. 2020).

The catalyst was investigated for its commercial applicability i.e., the activity of catalyst after regeneration for every experimental test run. The catalyst activity was judged based on the yield patterns of the process i.e., after every test run, the catalyst was calcined and used in the process to confirm the reusability. The catalyst was found to be reused up to 10 runs without any change in the yield patterns for the optimum parametric conditions. Catalyst activity found to be decreased after a 10th run which may be due to deactivation of catalyst. Initially, the total acidity of CAT-1 was 4.0 pKa which was approximately 0.05 meq amines/g CAT-1. After the 9th run, the acidity was increased to $\sim 5.5 \mathrm{pKa}$. Further acidification of catalyst was carried out and found to regain its acidity, but to check the commercial applicability, the reusability of CAT-1 up to 10th run without changing the catalyst bed was reported in the study.

\subsection{Analysis of liquid products extracted from plastic feedstock by pyrolysis process}




\subsubsection{FTIR of pyrolysis liquid fuels}

Figure 6 shows the FTIR spectra of alternate fuel obtained from pyrolysis of plastics feedstock. While the hydrocarbon fuel interacts with infrared light in the FTIR spectrometer, chemical bonds absorb specific wavelengths representing its structure and molecular bond strength. The spectra of all feedstock, i.e., LDPE, HDPE, PP, Mixed virgin plastic and domestic plastic waste, were almost similar

As shown in Fig. 6, The spectra of hydrocarbon fuels contain $\mathrm{C}-\mathrm{H}, \mathrm{C}=\mathrm{C}$, and $=\mathrm{C}-\mathrm{H}$ bonds. The presence of alkenes was spotted at 3138 and $3444 \mathrm{~cm}-1$ with = C-H stretching vibration with a strong peak signal. The wavenumber of $2922 \mathrm{~cm}-1$ shows the strong -C-H vibrational signal of alkanes present in the hydrocarbon fuel. The wavenumber of 1642, 1466, 1398, and $1376 \mathrm{~cm}-1$ showed the presence of alkene with $\mathrm{C}=\mathrm{C}$ vibrational bending, $\mathrm{C}=\mathrm{C}$ bending, and $-\mathrm{C}-\mathrm{H}$ stretching vibration signals. As the FTIR analysis provides only the idea of the presence of functional groups for the preliminary structure of chemical composition, the detailed chemical structural composition was identified using GC-MS analysis.

\subsubsection{GC-MS analysis}

The chemical composition of liquid hydrocarbons obtained from LDPE, HDPE, PP, Mixed virgin plastic, and domestic plastic waste was analyzed using GC-MS. The results revealed that the major components of the produced liquid hydrocarbon fuels were aliphatic (alkane, alkene, and alkyl compounds) carbon, ranging from C8- C20. It was observed from the Table 3 that major constitute of most of vergin plastics and domestic hydrocarbon was 1-Dodecene, 1-Decene, Undecane, Tetradecane and 1-Pentadecene, Pentadecane, 1-Heptadecene, Hexadecane. When individual virgin plastic (LDPE, HDPE, and PP) pyrolyzed, LDPE showed the maximum concentration of 1-Decene (12.43\%), Undecane (12.31\%), 1-Dodecene (9.13\%), Decane (8.58\%), 1Heptadecene (8.56\%), and Dodecane (6.65\%) while HDPE liquid fuel was with the major constituent of Pentadecane (11.71\%), 1-Pentadecene (10.58\%), 1-Heptadecene (9.09\%), Hexadecane (8.19\%) and 1-Dodecene (5.78\%). Furthermore, pp liquid fuel was majorly composed of 1-Octadecene (13.46\%), 1-Hexadecene (11.61\%), 1-Heptadecene (10.06\%), Hexadecane (12.46\%) and 1-Tetradecene (6.83\%). All the virgin plastics liquid hydrocarbons in the range of C8 to C20 with a major constituent alkene. In the case of mixed virgin plastic, 1-Pentadecene (9,08\%), Pentadecane (9.16\%), 1-Hexadecene (8.32\%), Hexadecane (8.52\%), and 1-Decene (6.8\%) appeared as significant hydrocarbons.

Domestic plastic waste's composition was almost similar to mixed virgin plastic. However, it showed a slightly different hydrocarbon composition. Dodecane (12.63\%), 1-Tridecene (9.96\%), Pentadecane (10.21\%), 1-Hexadecene (9.24\%), Tetradecane (5.97\%), and Tridecane (5.32\%) were the major hydrocarbons compared to mixed virgin plastics. In thermocatalytic pyrolysis, random scission of LDPE, HDPE, and PP occur, resulting in radicals. After that, $\beta$-scission of these radicals take place to produce a monomer which undergoes stabilization process by transfer of intramolecular or intermolecular hydrogen. Successive $\beta$-scission reactions of the secondary radicals lead to the creation of olefins and dienes. At the same time, the intermolecular hydrogen transfer results in the formation of paraffine. Due to the abundance of the hydrogen atom in the radical chain at elevated temperature, the probability of successive $\beta$-scission with intramolecular hydrogen transfer is highly expected (Das and Tiwari 2018). In addition, Dibutyl adipate, a specific oxygenated compound utilized generally as a plasticizer in the paint industry, was also identified in domestic liquid hydrocarbon fuels. These findings were in line with those obtained using FTIR.

On the other hand, when mixed virgin plastic and domestic plastic waste were pyrolyzed under the same temperature conditions using mineral clay as a catalyst, the results showed that catalyst favors the formation of alkanes. Due to catalytic reaction, alkanes increased from $43.66 \%$ to $58.55 \%$ and $48.35-61.5 \%$ in the case of mixed virgin plastic and domestic plastic waste, respectively. In addition, a slight increase in aromatics was also observed. Besides, wax formation is also reduced in liquid products, which may be due to the reason that clay is more acidic in nature and, therefore, leads to crack waxes (C13C28) into lighter hydrocarbon (Budsaereechai et al. 2019). 
Table 3

Chemical composition of liquid hydrocarbon fuel obtanined from LDPE, HDPE, PP, MVP and DPW

\begin{tabular}{|c|c|c|c|c|c|c|c|c|}
\hline Compound & $\begin{array}{l}\text { Molecular } \\
\text { Formula }\end{array}$ & LDPE & HDPE & PP & $\begin{array}{l}\text { mixed } \\
\text { virgin }\end{array}$ & $\begin{array}{l}\text { domestic } \\
\text { plastic waste } \\
\text { Wt (\%) }\end{array}$ & $\begin{array}{l}\text { Mixed vergin } \\
\text { plastic + } \\
\text { catalyst }\end{array}$ & $\begin{array}{l}\text { Domestic plastic } \\
\text { waste + catalyst }\end{array}$ \\
\hline 1-Octene & $\mathrm{C}_{8} \mathrm{H}_{16}$ & 1.78 & & & 1.35 & 0.81 & 0 & \\
\hline Toluene & $\mathrm{C}_{10} \mathrm{H}_{20}$ & 0 & & 4.05 & 5.26 & 1.01 & 3.43 & 4.98 \\
\hline Nonane & $\mathrm{C} 9 \mathrm{H} 2 \mathrm{O}$ & 3.01 & 2.41 & & 1.08 & & 1.98 & 2.2 \\
\hline 1-Nonene & $\mathrm{C}_{9} \mathrm{H}_{18}$ & 1.06 & 2.62 & & 3.16 & 3.52 & 2.76 & 1.45 \\
\hline 1-Decene & $\mathrm{C}_{10} \mathrm{H}_{20}$ & 12.43 & 4.14 & 2.57 & 6.8 & 3.84 & 4.87 & 2.08 \\
\hline Decane & $\mathrm{C}_{10} \mathrm{H}_{22}$ & 8.58 & 5.21 & 2.24 & 5.42 & 3.17 & 10.58 & 5.65 \\
\hline cyclodecane & $\mathrm{C}_{10} \mathrm{H}_{20}$ & & 5.76 & & 3.9 & & 2.26 & 1.99 \\
\hline 1-Undecene & $\mathrm{C}_{11} \mathrm{H}_{22}$ & & 5.47 & & 1.7 & 6.06 & 3.8 & 2.76 \\
\hline Undecane & $\mathrm{C}_{11} \mathrm{H}_{24}$ & 12.31 & 5.6 & 3.27 & 1.2 & 2.41 & 3.05 & 7.97 \\
\hline 1-Dodecene & $\mathrm{C}_{12} \mathrm{H}_{24}$ & 9.13 & 5.78 & 4.74 & 4.15 & 3.61 & 5.87 & 3.31 \\
\hline Dodecane & $\mathrm{C}_{12} \mathrm{H}_{26}$ & 6.65 & 3.65 & & 5.49 & 12.63 & 8.43 & 10.83 \\
\hline Tridecane & $\mathrm{C}_{13} \mathrm{H}_{28}$ & & & & 1.93 & 5.32 & 2.37 & 6.95 \\
\hline 1-Tridecene & $\mathrm{C}_{13} \mathrm{H}_{26}$ & 5.32 & 1.97 & 5.73 & 3.58 & 9.96 & 2.56 & 2.67 \\
\hline $\begin{array}{l}\text { 1- } \\
\text { Tetradecene }\end{array}$ & $\mathrm{C}_{14} \mathrm{H}_{28}$ & 2.02 & 5.23 & 6.83 & & 8.31 & & 5.32 \\
\hline Tetradecane & $\mathrm{C}_{14} \mathrm{H}_{30}$ & 6.55 & 4.66 & 5.09 & 5.83 & 5.97 & 6.54 & 5.87 \\
\hline $\begin{array}{l}\text { 1- } \\
\text { Pentadecene }\end{array}$ & $\mathrm{C}_{15} \mathrm{H}_{30}$ & 6.12 & 10.58 & 3.65 & 9.08 & 2.28 & 5.13 & 2.72 \\
\hline Pentadecane & $\mathrm{C}_{15} \mathrm{H}_{32}$ & & 11.71 & 6.82 & 9.16 & 10.21 & 9.14 & 9.31 \\
\hline $\begin{array}{l}\text { 1- } \\
\text { Hexadecene }\end{array}$ & $\mathrm{C}_{16} \mathrm{H}_{32}$ & 5.08 & & 11.61 & 8.32 & 5.24 & 5.3 & 3.91 \\
\hline $\begin{array}{l}\text { 1- } \\
\text { Heptadecene }\end{array}$ & $\mathrm{C}_{17} \mathrm{H}_{34}$ & 8.56 & 9.09 & 10.06 & 5.71 & 0.17 & 3.92 & \\
\hline Hexadecane & $\mathrm{C}_{16} \mathrm{H}_{34}$ & 3.61 & 8.19 & 12.46 & 8.52 & 2.62 & 7 & 8.31 \\
\hline $\begin{array}{l}\text { Dibutyl } \\
\text { adipate }\end{array}$ & $\mathrm{C}_{14} \mathrm{H}_{26} \mathrm{O}_{4}$ & & & & & 5.9 & & 5.01 \\
\hline Heptadance & $\mathrm{C}_{17} \mathrm{H}_{36}$ & 3.66 & 5.48 & 4.38 & 3.01 & 3.08 & 6.01 & 0.81 \\
\hline $\begin{array}{l}\text { 1- } \\
\text { Octadecene }\end{array}$ & $\mathrm{C}_{18} \mathrm{H}_{36}$ & 0 & 2.45 & 13.46 & 1.31 & & 1.6 & \\
\hline $\begin{array}{l}\text { 1- } \\
\text { Nonadecene }\end{array}$ & $\mathrm{C}_{19} \mathrm{H}_{38}$ & 2.06 & & 1.52 & 2.02 & 0.94 & & 2.3 \\
\hline Eicosane & $\mathrm{C} 2 \mathrm{OH} 42$ & 2.07 & & 1.52 & 2.02 & 2.94 & 3.4 & 3.6 \\
\hline
\end{tabular}


Liquid hydrocarbons fuel is subjected to various techniques to identify the physical and chemical structure. After obtaining the liquid hydrocarbons fuel, various tests are performed for its characteristics properties such as ultimate and proximate analysis, density, kinematic viscosity, pour point, flash point, moisture analysis and are depicted in Table 4. All the techniques are carried out as per the standards mentioned.

Liquid hydrocarbons from virgin HDPE plastic were found to be waxy, whereas PP and LDPE produced a clear liquid. Furthermore, the quality of the hydrocarbon fuel made from domestic plastic waste and mixed virgin plastic in this investigation was comparable to that of standard petroleum fuels, with kerosene and unpleasant odor and a dark brown color. This fuel color may be due to the presence of coloring and binding agents in the input feed. The produced hydrocarbon fuels, on the other hand, were free-flowing in nature and could be utilized directly for heating applications. Table 4 illustrates various properties such as density, kinematic viscosity, pour point, flash point, moisture content, and calorific value of the liquid hydrocarbon fuels from LDPE, HDPE, PP, mixed virgin plastic, and domestic plastic waste. The density of liquid hydrocarbon fuels derived LDPE, HDPE, PP, mixed virgin plastic, and domestic plastic waste was $0.89 \mathrm{~g} / \mathrm{cc}, 0.92 \mathrm{~g} / \mathrm{cc}, 0.86 \mathrm{~g} / \mathrm{cc}, 0.91 \mathrm{~g} / \mathrm{cc}$ and $0.86, \mathrm{~g} / \mathrm{cc}$ respectively in comparison to gasoline $(0.78 \mathrm{~g} / \mathrm{cc})$ and diesel $(0.807 \mathrm{~g} / \mathrm{cc})$. Similarly, the kinematic viscosity of LDPE (3.98 cSt), HDPE (5.08 cSt), PP (4.09 cSt), mixed virgin plastic (4.53 cSt), and domestic plastic waste hydrocarbon fuels (4.48 cSt) was lower than MVP fuel (4.53 cSt); nonetheless, it was in the range of ASTM standards (2-6 cSt). Other properties such as flash point were also found to be lesser for individual virgin plastics (LDPE $-30^{\circ} \mathrm{C}, \mathrm{HDPE}-34^{\circ} \mathrm{C}, \mathrm{PP}-29^{\circ} \mathrm{C}$ ) compared to mixed virgin plastic $\left(40^{\circ} \mathrm{C}\right.$ and domestic plastic waste $\left(35^{\circ} \mathrm{C}\right)$. The values of flash point for diesel and gasoline were observe to be $52^{\circ} \mathrm{C}$ and $42^{\circ} \mathrm{C}$ respectively, which in agreement with other research(Chandran et al. 2020; Rajendran et al. 2020). On the other hand, the calorific value of mixed virgin plastic and domestic waste plastic was $44.61 \mathrm{MJ} / \mathrm{kg}$ and 43.92 $\mathrm{MJ} / \mathrm{kg}$, respectively, compared to diesel $(45.21 \mathrm{MJ} / \mathrm{kg})$ and gasoline $(47.64 \mathrm{MJ} / \mathrm{kg})$. Moreover, the calorific value of individual virgin plastics, i.e., LDPE (45.72 MJ/kg), HDPE (45.59 MJ/kg), and PP (43.63 MJ/kg) was also in the range of the values obtained for diesel and gasoline. Calorific value is one of the main properties of fuel that highly affects combustion. Similar results for calorific value of LDPE, HDPE, and PP were also obtained by Budsaereechai et al. 2019. Table 4 shows a comparison of the pour points of the resulting hydrocarbon fuels and commercial fuels. Due to the high volatility of the sample, the pour point of gasoline was not examined in this study. The pour point of pyrolytic liquid fuels derived from mixed virgin plastic and domestic plastic waste was poor than diesel fuel. The diesel index is a measurement of a diesel fuel's ignition efficiency. It is calculated on the basis of the sample's specific gravity and aniline point. In the present study, the diesel index of plastic hydrocarbon fuels was 42.5 (LDPE), 38.01(HDPE), 40.23 PP), 38.54 (mixed virgin plastic), and 35.34 (domestic plastic waste). These values are in good agreement with the standard value of diesel (40). Based on these fuel properties, it can be observed that liquid hydrocarbon fuels derived either from virgin plastic or plastic waste, have an excellent potential to use as an alternative fuel. 
Table 4

Characteristics properties of alternate fuel obtained from different plastic

\begin{tabular}{|c|c|c|c|c|c|c|c|}
\hline Parameter & PP & LDPE & HDPE & $\begin{array}{l}\text { Mixed virgin } \\
\text { plastic }\end{array}$ & $\begin{array}{l}\text { Domestic } \\
\text { plastic waste }\end{array}$ & Gasoline & Diesel \\
\hline Appearance & $\begin{array}{l}\text { Pale } \\
\text { yellow }\end{array}$ & $\begin{array}{l}\text { Pale } \\
\text { yellow }\end{array}$ & $\begin{array}{l}\text { Dark } \\
\text { brown }\end{array}$ & Brown & Dark brown & No color & $\begin{array}{l}\text { Pale } \\
\text { yellow }\end{array}$ \\
\hline Moisture (\% v/v) (ASTM D95) & 0 & 0 & 0 & 0 & 2.4 & $0.4-0.5$ & $\begin{array}{l}0.1- \\
0.3\end{array}$ \\
\hline API gravity @ 60F (ASTM D287) & 33.03 & 27.48 & 34.21 & 36.72 & 39.6 & 55 & 38 \\
\hline $\begin{array}{l}\text { Density @ } 15^{\circ} \mathrm{C} \mathrm{g} / \mathrm{cc} \text { (ASTM } \\
\text { D4052-16) }\end{array}$ & 0.86 & 0.89 & 0.92 & 0.91 & 0.86 & 0.78 & 0.807 \\
\hline $\begin{array}{l}\text { Kinematic viscosity @ } 40^{\circ} \mathrm{C} \text { (cSt) } \\
\text { (ASTM D445) }\end{array}$ & 4.09 & 3.98 & 5.08 & 4.53 & 4.48 & 1.17 & $2-4.5$ \\
\hline $\begin{array}{l}\text { Gross heat of combustion } \\
(\mathrm{MJ} / \mathrm{kg})(\text { ASTM D240-17) }\end{array}$ & 45.72 & 45.59 & 43.63 & 44.61 & 43.92 & 47.64 & 45.21 \\
\hline $\begin{array}{l}\text { Conradson carbon residue (\% wt) } \\
\text { (ASTM D189) }\end{array}$ & 0.12 & 0.19 & 0.11 & 0.15 & 0.15 & 0.14 & 0.35 \\
\hline Ash (\% wt) (ASTM D482) & 0.013 & 0 & 0 & 0.11 & 0.013 & 0.001 & 0.01 \\
\hline Pour point $\left({ }^{\circ} \mathrm{C}\right)$ (ASTM D97) & -9 & -10 & 35 & 30 & 18 & - & 6 \\
\hline Flash Point $\left({ }^{\circ} \mathrm{C}\right)$ (ASTM D93) & 30 & 48 & 29 & 40 & 35 & 42 & 52 \\
\hline Aniline point $\left({ }^{\circ} \mathrm{C}\right)$ & 40 & 45 & 50 & 50 & 60 & 71 & 77.5 \\
\hline Diesel index & 42.5 & 38.01 & 40.23 & 38.54 & 35.34 & - & 40 \\
\hline
\end{tabular}

\subsection{Gas analysis obtained from pyrolysis of plastic waste}

The gases from the pyrolysis of plastic feedstock were analyzed and represented in Table 5. the results revealed that the composition of gases derived from the pyrolysis of the mixed virgin plastic and domestic plastic waste was almost similar. Alkane and alkene hydrocarbon gases from C1-C4 were observed in significant amounts in pyrolytic gases. These gases result from the irregular scission of larger hydrocarbon groups at a higher temperature. These gases are also possible if condensable gases undergo secondary cracking reactions in the main reactor for longer The GC results showed that pyrolytic gases derived from individual virgin plastics have hydrocarbons such as ethene and propene as a major product. In addition, some traces of hydrogen gas is also identified in pryolytic gases. However, LDPE, HDPE, PP, and mixed virgin plastic showed no CO and CO2 in pyrolytic gaseous composition. However, a small traces of $\mathrm{CO}$ and $\mathrm{CO} 2$ were examined in domestic plastic waste, which may be due to impurities, binder, filler, or coloring agent. Butene was also observed in the least amount for all types of plastic pyrolytic gases. Unsaturated hydrocarbons such as ethene, propylene, and butene, as well as their derivatives, were also investigated, which are generated by the random scission degradation of plastic followed by the stabilization of intermediate radicals (Das and Tiwari 2018). The gross and net calorific value of pyrolytic gases obtained from virgin and domestic plastic wastes was observed in the range of $66.74 \mathrm{MJ} / \mathrm{m} 3$ to $75.61 \mathrm{MJ} / \mathrm{m} 3$ which confirm that thsese pyrolytic gases can be used as fuel gas for heating and engines. The pyrolytic gas composition obtained from virgin plastics and domestic plastic waste were found to be consistent with other studies carried out different researchers (Singh and Ruj 2016; Das and Tiwari 2018; Zhang et al. 2019). Furthermore, Furthermore, the pyrolytic gases have good potential to utilize in turbine for power generation or can be used directly to boilers as a substitute for coal without any additional pretreatment. 
Table 5

Non-condensable gas composition of plastic feedstock (wt\%)

\begin{tabular}{|llllll|}
\hline Plastic & LDPE & HDPE & PP & Mixed virgin plastic & Domestic plastic waste \\
\hline Hydrogen & 0.31 & 0.46 & 0.96 & 1.58 & 0.45 \\
\hline Carbon dioxide & 0 & 0 & 0 & 0 & 0.82 \\
\hline Carbon monoxide & 0 & 0 & 0 & 0 & 0.44 \\
\hline Methane & 7.47 & 9.28 & 1.48 & 6.07 & 7.6 \\
\hline Ethane & 12.1 & 11.56 & 14.42 & 11.69 & 12.12 \\
\hline Ethene & 27.99 & 26.41 & 38.65 & 31.02 & 27.41 \\
\hline Propane & 8.1 & 8.67 & 8.87 & 8.55 & 8.44 \\
\hline Propene & 26.34 & 26.74 & 29.9 & 27.66 & 26.71 \\
\hline Butane & 2.52 & 1.51 & 1.67 & 1.9 & 1.98 \\
\hline Butane & 15.17 & 15.37 & 4.05 & 11.53 & 14.03 \\
\hline Gross calorific value $\left(\mathrm{MJ}^{\left.-\mathrm{nm}^{3}\right)}\right.$ & 69.99 & 69.02 & 75.61 & 70.97 & 69.38 \\
\hline Net calorific value $\left(\mathrm{MJ} / \mathrm{nm}^{3}\right)$ & 67.49 & 66.60 & 71.02 & 67.84 & 66.74 \\
\hline
\end{tabular}

\subsection{Potential application of liquid and gaseous fuel obtained from pyrolysis of plastic waste}

According to the definition of different transportation fuels, hydrocarbon fuel can be categorized into C5-C10, C11-C20, and C8C16, which are corresponds to gasoline, diesel, and jet range hydrocarbons, respectively. In this investigation, the hydrocarbon range of gasoline i.e. C5-C10 was $26.86 \%, 20.14 \%$ and $8.86 \%$ for LDPE, HDPE, and PP virgin polymers, respectively. In addition, the pyrolysis of mixed virgin plastic and domestic plastic waste resulted in liquid hydrocarbon fuels having $25.88 \%$ and $18.35 \%$ similarity with gasoline (Table 6). The Physico-chemical properties of liquid fuels obtained from plastic wastes are compared with gasoline and diesel fuels in Table 4. Dobo et al. 2019 carried out pyrolysis of HDPE, LDPE, PP, PS, PET, and plastic wastes and tested pyrolytic oil in an SI engine without any modifications or fuel blending. They obtained good results of engine performance and emissions (Dobó et al. 2019). Similarly, Kumar et al. received improved emissions in SI engine fueled with plastic waste pyrolysis oil (Kumar et al. 2016). On the other hand, C10 - C20 was the mixture of alkane and alkene observed more than $70 \%$ for all types of plastic feedstock. Based on chemical composition predicted from GC-MS and FTIR, it was examined that LDPE, HDPE, PP, mixed virgin plastic, and domestic plastic waste showed $71.07 \%, 79.86 \%, 89.62 \% 71.01 \%$ and $84.71 \%$ similarity with diesel fuels. (Table 6) Most of the fuel properties of hydrocarbons fuels extracted from virgin plastics and domestic plastics were also found to be closer to diesel fuels than gasoline, which is compared in Table 4. Singh et al. 2020 performed pyrolysis of mixed waste plastic and ran a diesel engine with $50 \%$ plastic diesel fuel blends without increasing CO emissions (Singh et al. 2020). Kalargariscan et al. also tested performance and emissions with plastic oil extracted by the thermochemical pyrolysis process. They concluded that plastic oil has an excellent potential to use as an alternative fuel in $\mathrm{Cl}$ engines (Kalargaris et al. 2017).

Currently, jet fuel production from plastic waste through catalytic pyrolysis has attracted significant attention (Huo et al. 2020). In the present study, hydrocarbons obtained from different plastic feedstock were also similar to jet fuels hydrocarbon range from $37 \%$ to $43 \%$ when no catalyst was used (Table 6). According to Gutiérrez-Antonio et al., 2017, Fossil jet fuel generally includes approximately $20 \%$ aromatics, $40 \%$ isoparaffins, $20 \%$ naphthenes and $20 \%$ paraffin. Here, hydrocarbons such as alkane, cycloalkanes and aromatics in the range of C8-C16 were included to get similarity with jet fuels. Mixed virgin plastic showed more similarity (46.71\%) with jet fuels than domestic plastic waste (43.34 \%). However, when mineral clay was used as a catalyst, mixed verging plastic showed only $6.09 \%$ improvement in jet fuel range hydrocarbon, while domestic 
plastic waste showed an increment from 43.34-61.86\% jet fuel range hydrocarbons, which may be due to the synergetic effect of all these types of plastic and other impurities such as a binder, filler, and coloring agent leading more productions of alkane, cycloalkane and aromatic in presence of catalyst. During catalyst loading in the reaction, it is assumed that the catalyst is to be unable to provide enough active sites for aromatization and oligomerization reactions, resulting in a large amount of aliphatic hydrocarbon being generated (Zhang et al. 2017, 2019). However, these fuels cannot be used in jet fuel engine directly and need to add some amounts of aromatic and cycloalkanes.

Table 6

composition and feasible application of liquid hydrocarbons obtained from LDPE, HDPE, PP, MVP and DPW

\begin{tabular}{|c|c|c|c|c|c|c|c|c|}
\hline \multirow{2}{*}{$\begin{array}{l}\text { Plastic } \\
\text { type }\end{array}$} & \multicolumn{5}{|c|}{ Composition of liquid hydrocarbons (\%) } & \multirow{2}{*}{$\begin{array}{l}\text { Gasoline } \\
\text { range } \\
\text { hydrocarbon } \\
\text { (C5-C10), wt } \\
\%\end{array}$} & \multirow{2}{*}{$\begin{array}{l}\text { Diesel range } \\
\text { hydrocarbon } \\
\text { (C11-C20), } \\
\text { wt \% }\end{array}$} & \multirow{2}{*}{$\begin{array}{l}\text { Jet fuel } \\
\text { range } \\
\text { hydrocarbon } \\
\text { (C8-C18, } \\
\text { alkane and } \\
\text { aromatics), } \\
\text { wt \% }\end{array}$} \\
\hline & Alkene & alkane & Aromatics & Cycloakane & $\begin{array}{l}\text { Oxyginated } \\
\text { hydrocarbon }\end{array}$ & & & \\
\hline LDPE & 53.56 & 46.44 & 0 & 0 & 0 & 26.86 & 71.07 & 37.7 \\
\hline HDPE & 47.33 & 46.91 & 0 & 5.76 & 0 & 20.14 & 79.86 & 44.78 \\
\hline PP & 60.17 & 35.78 & 4.05 & 0 & 0 & 8.86 & 89.62 & 33.93 \\
\hline $\begin{array}{l}\text { mixed } \\
\text { virgin } \\
\text { plastic }\end{array}$ & 47.18 & 43.66 & 5.26 & 3.9 & 0 & 26.97 & 71.01 & 46.71 \\
\hline $\begin{array}{l}\text { domestic } \\
\text { plastic } \\
\text { waste Wt } \\
(\%)\end{array}$ & 44.74 & 48.35 & 1.01 & 0 & 5.9 & 12.35 & 84.71 & 43.34 \\
\hline $\begin{array}{l}\text { Mixed } \\
\text { vergin } \\
\text { plastic + } \\
\text { catalyst }\end{array}$ & 35.81 & 58.5 & 3.43 & 2.26 & 0 & 25.88 & 70.72 & 52.8 \\
\hline $\begin{array}{l}\text { Domestic } \\
\text { plastic } \\
\text { waste + } \\
\text { catalyst }\end{array}$ & 26.52 & 61.5 & 4.98 & 1.99 & 5.01 & 18.35 & 78.05 & 61.86 \\
\hline
\end{tabular}

\section{Conclusions}

Pyrolysis of individual and mixed virgin plastic is compared with domestic plastic waste collected from UPES, University. This study has demonstrated the production of various grades of hydrocarbons fuels from individual virgin plastics (LDPE, HDPE and PP), mixed virgin plastic, and domestic plastic waste at the temperature range $473 \mathrm{~K}$ to $973 \mathrm{~K}$. All types of plastic feedstock showed more similarity with diesel fuel hydrocarbons. However, when mineral clay was applied as a catalyst to mixed virgin plastic and domestic plastic waste, jet fuel range hydrocarbon similarity improve $6.09 \%$ and $9.46 \%$, respectively. Additionally, gas fuel products from pyrolysis of domestic plastic waste and virgin plastic feedstock contain C1-C4 hydrocarbons that have high calorific value compared to other sources (biomass). Hence, catalytic conversions of plastics using inexpensive catalysts provide an innovative and feasible refinery pathway, explicitly targeting jet fuels range hydrocarbon fuels.

\section{Declarations}

\section{Acknowledgment}


Authors are very thankful to Dr SJ Chopra, (Chancellor, UPES), Dr D K Avasthi (Dean, R \& D) and Dr Bhawan Lamba (HOD chemistry), for providing continue support and providing analysis facilities in UPES, Bidholi campus, Dehradun, UK, India. We are also thankful for Central Instrumentation Centre (CIC), R \& D, UPES for FTIR and GC-MS analysis.

Funding: This work is funded and supported by the Science and Engineering Research Board (SERB), DST, New Delhi - 110 070 (Project file No. ECR/2017/000185).

Availability of data and materials: Data can be made available on request.

\section{Compliance with ethical standards}

Competing interests: The authors declare that they have no competing interests

Ethics approval and consent to participate: It is not applicable to this manuscript.

Consent for publication: The authors declare their consent to publish this article.

\section{Authors Contributions}

Conceptualization: Praveen Kumar Ghodke; Methodology: Krishna Moorth; Formal analysis and investigation: Praveen Kumar Ghodke, Amit Kumar Sharma, Writing - original draft preparation: Praveen Kumar Ghodke, Amit Kumar Sharma; Writing - review and editing: Wei-Hsin Chen, Funding acquisition: Praveen Kumar Ghodke; Resources: Praveen Kumar Ghodke, Amit Kumar Sharma, Supervision: Praveen Kumar Ghodke

\section{References}

1. Abbas AS, Shubar SDA (2008) Pyrolysis of High-density Polyethylene for the Production of Fuel-like Liquid Hydrocarbon. IJCPE Iraqi J Chem Pet Eng 99:23-29

2. Achilias DS, Roupakias $C$, Megalokonomos $P$ et al (2007) Chemical recycling of plastic wastes made from polyethylene (LDPE and HDPE) and polypropylene (PP). J Hazard Mater 149:536-542. https://doi.org/10.1016/j.jhazmat.2007.06.076

3. Adrados a., de Marco I, Caballero BM et al (2012) Pyrolysis of plastic packaging waste: A comparison of plastic residuals from material recovery facilities with simulated plastic waste. Waste Manag 32:826-832. https://doi.org/10.1016/j.wasman.2011.06.016

4. Ahmad N, Ahmad N, Maafa IM et al (2020) Thermal conversion of polystyrene plastic waste to liquid fuel via ethanolysis. Fuel 279:118498. https://doi.org/10.1016/j.fuel.2020.118498

5. Al-Salem SM, Lettieri P, Baeyens J (2009) Recycling and recovery routes of plastic solid waste (PSW): A review. Waste Manag 29:2625-2643. https://doi.org/10.1016/j.wasman.2009.06.004

6. Artetxe M, Lopez G, Amutio M et al (2010) Operating Conditions for the Pyrolysis of Poly-(ethylene terephthalate) in a Conical Spouted-Bed Reactor. Ind Eng Chem Res 49:2064-2069. https://doi.org/10.1021/ie900557c

7. Bharathy S, Gnanasikamani B, Radhakrishnan Lawrence K (2019) Investigation on the use of plastic pyrolysis oil as alternate fuel in a direct injection diesel engine with titanium oxide nanoadditive. Environ Sci Pollut Res 26:10319-10332. https://doi.org/10.1007/s11356-019-04293-0

8. Breyer S, Mekhitarian L, Rimez B, Haut B (2017) Production of an alternative fuel by the co-pyrolysis of landfill recovered plastic wastes and used lubrication oils. Waste Manag. https://doi.org/10.1016/j.wasman.2016.12.011

9. Budsaereechai S, Hunt AJ, Ngernyen Y (2019) Catalytic pyrolysis of plastic waste for the production of liquid fuels for engines. RSC Adv 9:5844-5857. https://doi.org/10.1039/C8RA10058F

10. Chandran M, Tamilkolundu S, Murugesan C (2020) Conversion of plastic waste to fuel

11. Dai L, Fan L, Duan D et al (2017) Production of hydrocarbon-rich bio-oil from soapstock via fast microwave-assisted catalytic pyrolysis. J Anal Appl Pyrolysis. https://doi.org/10.1016/j.jaap.2017.03.003 
12. Damodharan D, Sathiyagnanam AP, Rana D et al (2018) Effective utilization of waste plastic oil in a direct injection diesel engine using high carbon alcohols as oxygenated additives for cleaner emissions. Energy Convers Manag 166:81-97. https://doi.org/10.1016/j.enconman.2018.04.006

13. Das P, Tiwari P (2018) Valorization of packaging plastic waste by slow pyrolysis. Resour Conserv Recycl 128:69-77. https://doi.org/10.1016/j.resconrec.2017.09.025

14. Demirbas A (2004) Pyrolysis of municipal plastic wastes for recovery of gasoline-range hydrocarbons. J Anal Appl Pyrolysis 72:97-102. https://doi.org/10.1016/j.jaap.2004.03.001

15. Dobó Z, Jakab Z, Nagy G et al (2019) Transportation fuel from plastic wastes: Production, purification and SI engine tests. Energy 189:. https://doi.org/10.1016/j.energy.2019.116353

16. Hazrat MA, Rasul MG, Khan MMK et al (2014) Utilization of Polymer Wastes as Transport Fuel Resources- a Recent Development. Energy Procedia 61:1681-1685. https://doi.org/10.1016/j.egypro.2014.12.191

17. Honus S, Kumagai S, Němček O, Yoshioka T (2016) Replacing conventional fuels in USA, Europe, and UK with plastic pyrolysis gases - Part I: Experiments and graphical interchangeability methods. Energy Convers Manag 126:1128-1145. https://doi.org/https://doi.org/10.1016/j.enconman.2016.08.055

18. Huo E, Lei H, Liu C et al (2020) Jet fuel and hydrogen produced from waste plastics catalytic pyrolysis with activated carbon and MgO. Sci Total Environ 727:138411. https://doi.org/10.1016/j.scitotenv.2020.138411

19. Jahnavi N, Kanmani K, Kumar PS, Varjani S (2020) Conversion of waste plastics into low emissive hydrocarbon fuel using catalyst produced from biowaste

20. Kalargaris I, Tian G, Gu S (2017) Combustion, performance and emission analysis of a DI diesel engine using plastic pyrolysis oil. Fuel Process Technol 157:108-115. https://doi.org/10.1016/j.fuproc.2016.11.016

21. Kumar KV, Puli RK, Swarna Kumari A, Shailesh P (2016) Performance and emission studies of a si engine using distilled plastic pyrolysis oil-petrol blends. MATEC Web Conf 45:. https://doi.org/10.1051/matecconf/20164503002

22. Kumar S, Panda AK, Singh RK (2011) A review on tertiary recycling of high-density polyethylene to fuel. Resour Conserv Recycl 55:893-910. https://doi.org/10.1016/j.resconrec.2011.05.005

23. Miandad R, Barakat MA, Aburiazaiza AS et al (2017a) Effect of plastic waste types on pyrolysis liquid oil. Int Biodeterior Biodegrad 119:239-252. https://doi.org/10.1016/j.ibiod.2016.09.017

24. Miandad R, Barakat MA, Rehan M et al (2017b) Plastic waste to liquid oil through catalytic pyrolysis using natural and synthetic zeolite catalysts. Waste Manag 69:66-78. https://doi.org/10.1016/j.wasman.2017.08.032

25. Miskolczi N, Bartha L, Deák G, Jóver B (2004) Thermal degradation of municipal plastic waste for production of fuel-like hydrocarbons. Polym Degrad Stab 86:357-366. https://doi.org/10.1016/j.polymdegradstab.2004.04.025

26. Park KB, Jeong YS, Guzelciftci B, Kim JS (2019) Characteristics of a new type continuous two-stage pyrolysis of waste polyethylene. Energy 166:343-351. https://doi.org/10.1016/j.energy.2018.10.078

27. Părpăriţă E, Brebu M, Azhar Uddin M et al (2014) Pyrolysis behaviors of various biomasses. Polym Degrad Stab 100:1-9. https://doi.org/10.1016/j.polymdegradstab.2014.01.005

28. Quesada L, Calero M, Martín-Lara MA et al (2019) Characterization of fuel produced by pyrolysis of plastic film obtained of municipal solid waste. Energy 186:. https://doi.org/10.1016/j.energy.2019.115874

29. Rafey A, Siddiqui FZ (2021) A review of plastic waste management in India-challenges and opportunities. Int J Environ Anal Chem 00:1-17. https://doi.org/10.1080/03067319.2021.1917560

30. Rajamohan S, Kasimani R (2018) Analytical characterization of products obtained from slow pyrolysis of Calophyllum inophyllum seed cake: study on performance and emission characteristics of direct injection diesel engine fuelled with bio-oil blends. Environ Sci Pollut Res 25:9523-9538

31. Rajendran KM, Chintala V, Sharma A et al (2020) Review of Catalyst materials in achieving the liquid hydrocarbon fuels from municipal mixed plastic waste (MMPW). Mater Today Commun 100982

32. Ruiz M, Martin E, Blin J et al (2017) Understanding the Secondary Reactions of Flash Pyrolysis Vapors inside a Hot Gas Filtration Unit. Energy Fuels 31:13785-13795. https://doi.org/10.1021/acs.energyfuels.7b02923

Page 16/22 
33. Shah SH, Khan ZM, Raja IA et al (2010) Low temperature conversion of plastic waste into light hydrocarbons. J Hazard Mater 179:15-20. https://doi.org/10.1016/j.jhazmat.2010.01.134

34. Sharuddin SDA, Abnisa F, Wan Mohd Ashri Wan Daud MKA (2017) Energy recovery from pyrolysis of plastic waste: Study on non-recycled plastics (NRP) data as the real measure of plastic waste. Energy Convers Manag 148:925-934. https://doi.org/10.1016/j.enconman.2017.06.046

35. Siddiqui MN, Redhwi HH (2009) Pyrolysis of mixed plastics for the recovery of useful products. Fuel Process Technol 90:545-552. https://doi.org/10.1016/j.fuproc.2009.01.003

36. Singh RK, Ruj B (2016) Time and temperature depended fuel gas generation from pyrolysis of real world municipal plastic waste. Fuel 174:164-171. https://doi.org/10.1016/j.fuel.2016.01.049

37. Singh RK, Ruj B, Sadhukhan AK et al (2020) Waste plastic to pyrolytic oil and its utilization in Cl engine: Performance analysis and combustion characteristics. Fuel 262:116539. https://doi.org/10.1016/j.fuel.2019.116539

38. T.Williams P, Slaney E (2007) Analysis of products from the pyrolysis and liquefaction of single plastics and waste plastic mixtures. Resour Conserv Recycl 51:754-769

39. Thahir R, Altway A, Juliastuti SR, Susianto (2019) Production of liquid fuel from plastic waste using integrated pyrolysis method with refinery distillation bubble cap plate column. Energy Reports 5:70-77. https://doi.org/10.1016/j.egyr.2018.11.004

40. Tomasek S, Varga Z, Hancsók J (2020) Production of jet fuel from cracked fractions of waste polypropylene and polyethylene. Fuel Process Technol 197:106197. https://doi.org/10.1016/j.fuproc.2019.106197

41. Tulashie SK, Boadu EK, Dapaah S (2019) Plastic waste to fuel via pyrolysis: A key way to solving the severe plastic waste problem in Ghana. Therm Sci Eng Prog 11:417-424. https://doi.org/10.1016/j.tsep.2019.05.002

42. Yurdakoç M, Akçay M, Tonbul Y, Yurdakoç K (1999) Acidity of silica-alumina catalysts by amine titration using Hammett indicators and FT-IR study of pyridine adsorption. Turkish J Chem 23:319-327

43. Zhang X, Lei H, Zhu L et al (2017) From plastics to jet fuel range alkanes via combined catalytic conversions. Fuel 188:28-38. https://doi.org/10.1016/j.fuel.2016.10.015

44. Zhang Y, Duan D, Lei H et al (2019) Jet fuel production from waste plastics via catalytic pyrolysis with activated carbons. Appl Energy 251:113337. https://doi.org/10.1016/j.apenergy.2019.113337

\section{Figures}



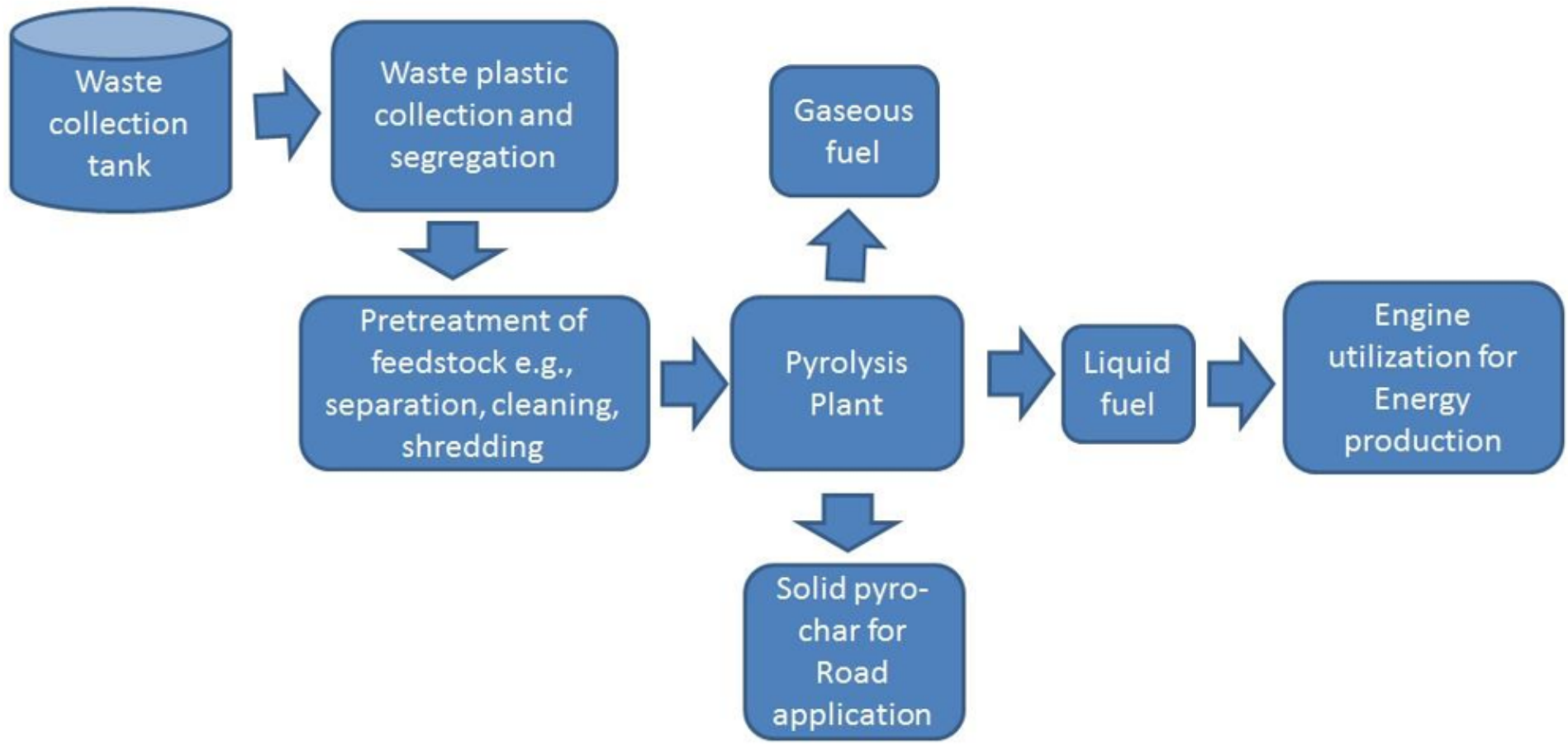

\section{Figure 1}

Process pathway for production of hydrocarbon fuels from domestic plastic waste and virgin plastics 

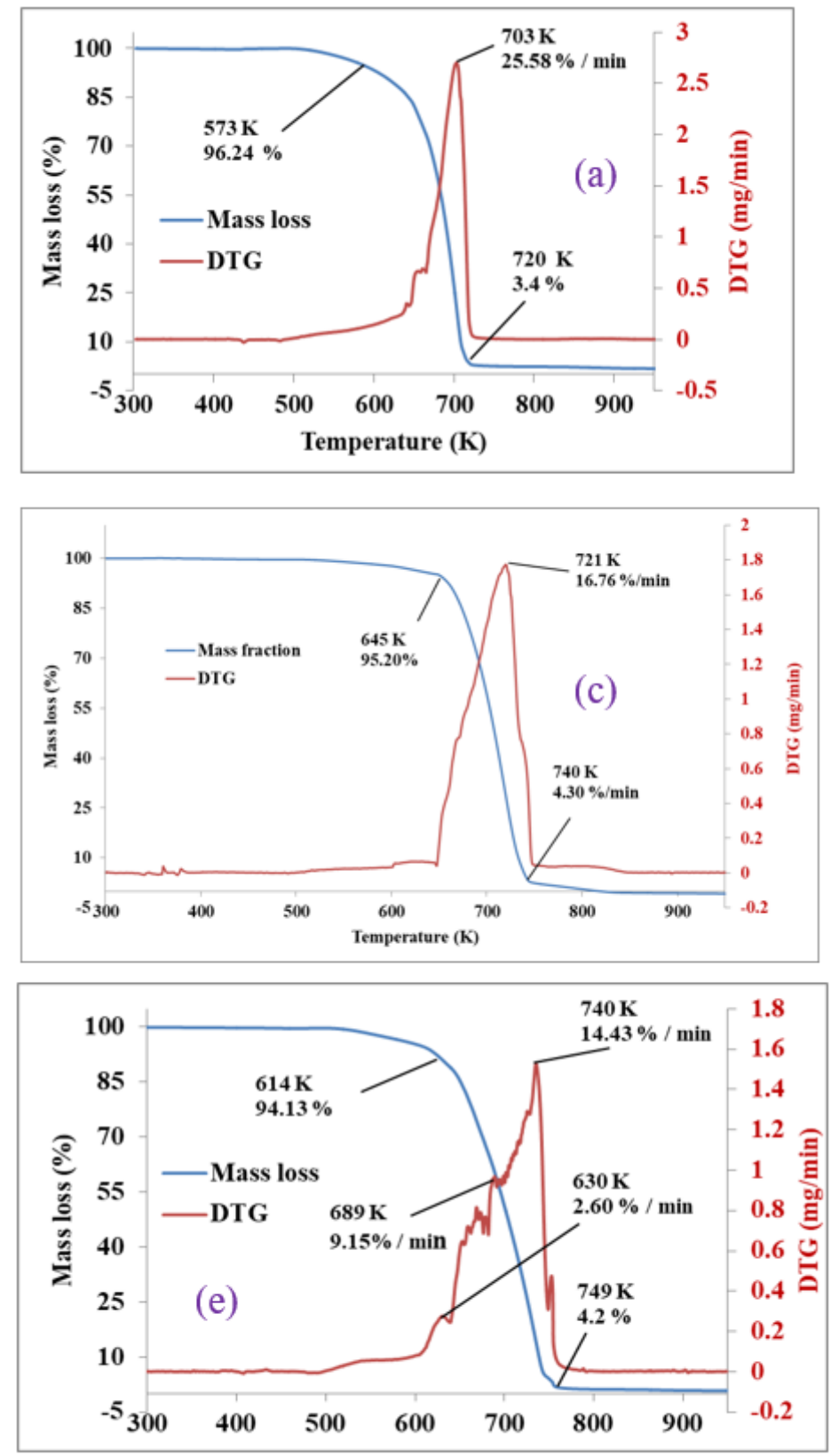
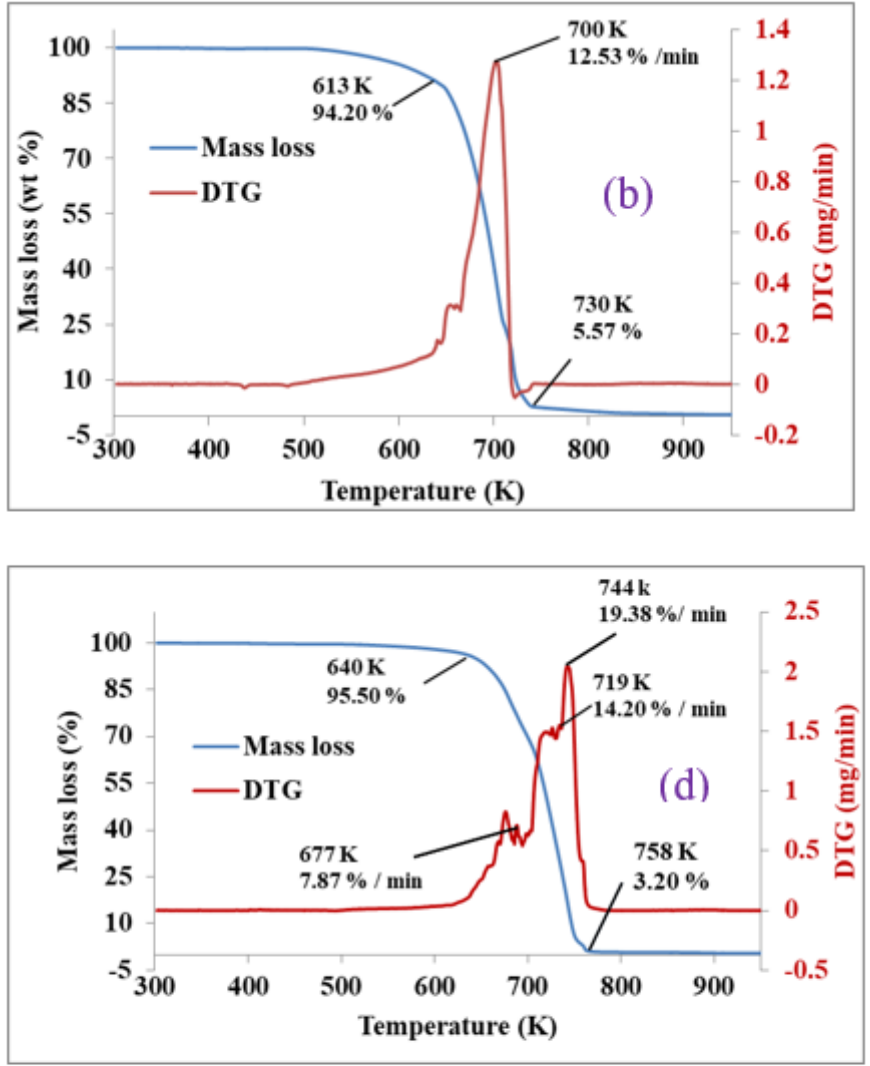

\section{Figure 2}

Thermo gravimetric (TG) and differential thermo gravimetric (DTG) analysis of (a) LDPE (b) HDPE (c) PP (d) Mixed vergin plastic (e) Domestic plastic waste 


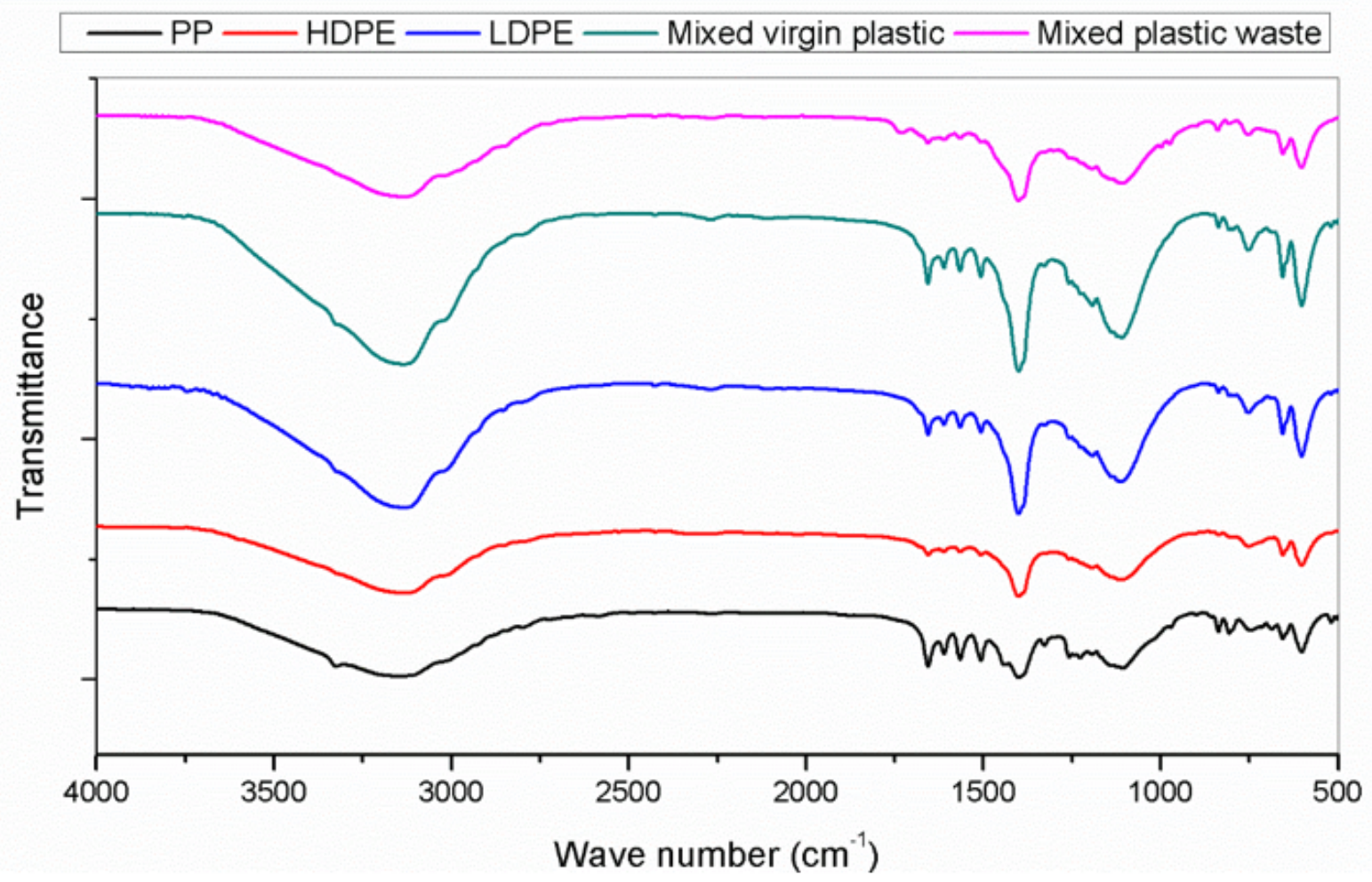

Figure 3

Fourier transformed Infrared spectra of plastic feedstock

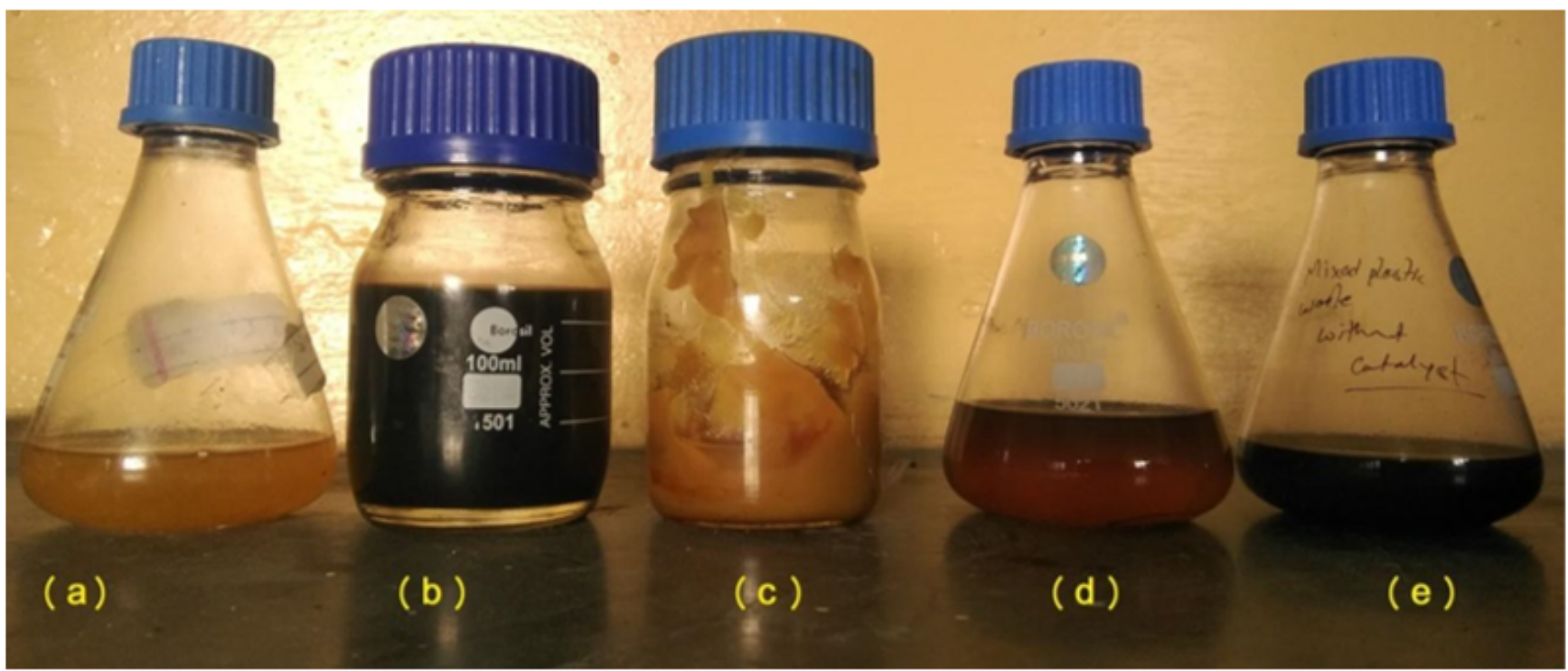

Figure 4

Different alternate fuels produced from (a) PP (b) LDPE (c) HDPE (d) Mixed virgin plastic (e) Domestic plastic waste (all products shown are produced @ optimum temperature condition) 

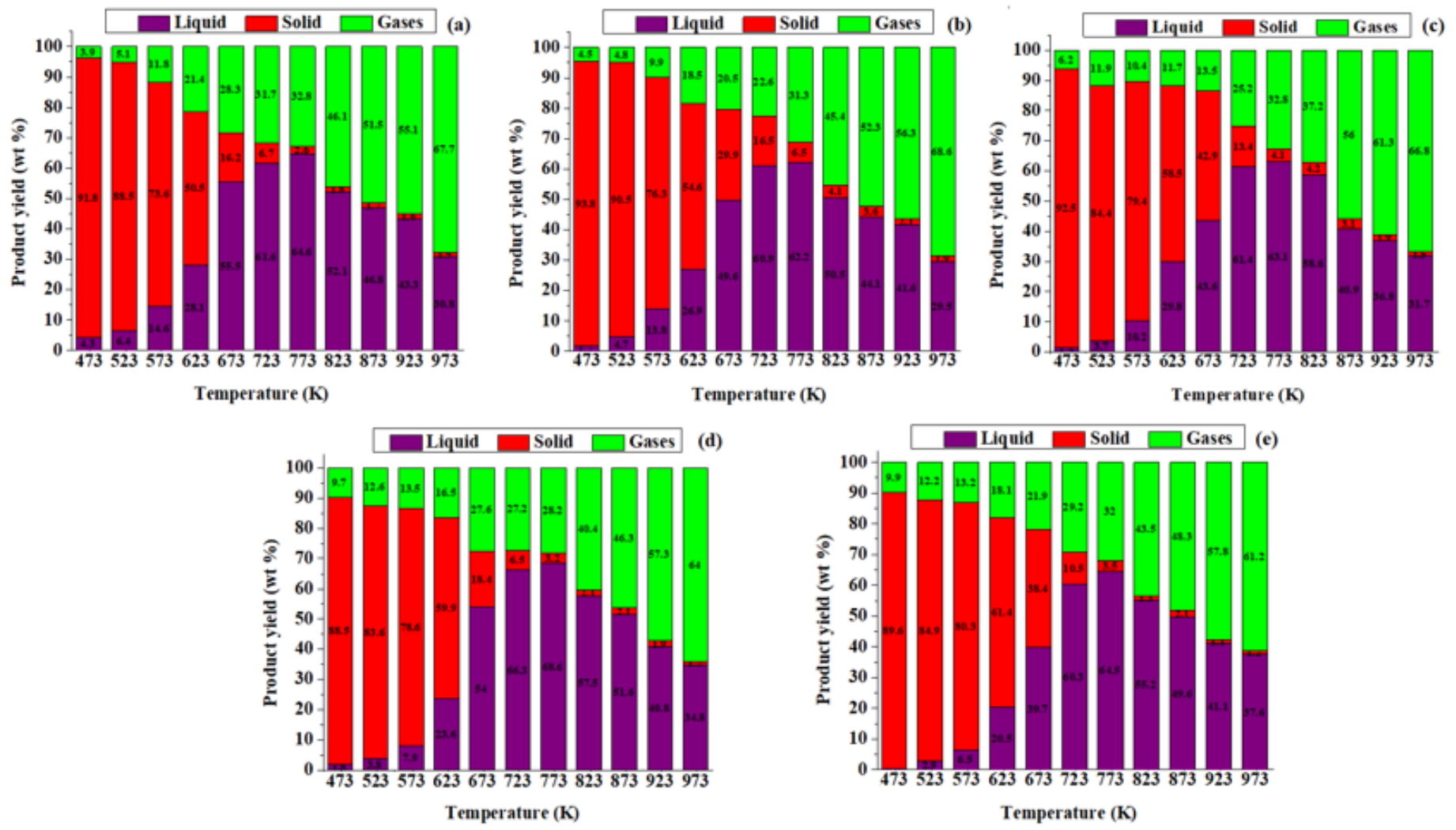

Figure 5

Product yield obtained from pyrolysis of LDPE, HDPE, PP, MVP and DPW
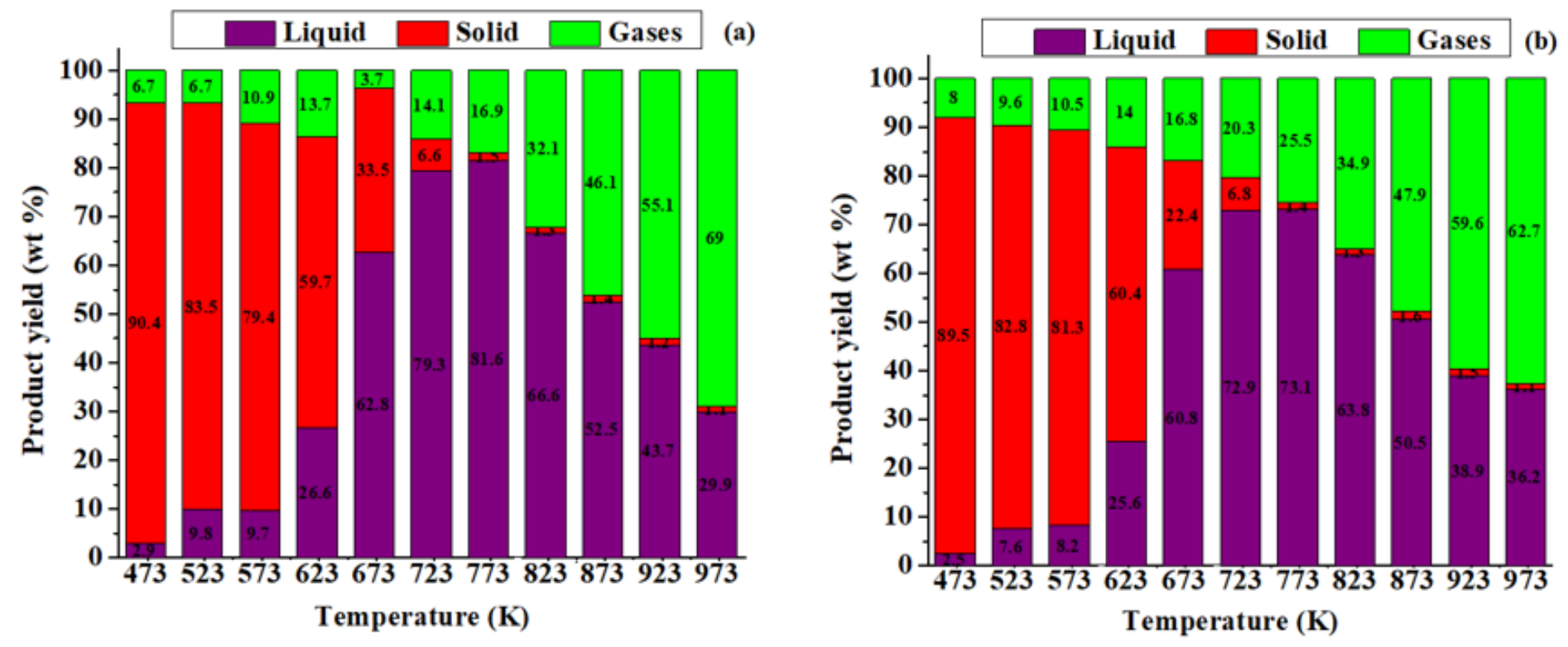

Figure 6

Product yield obtained from pyrolysis of MVP and DPW in presence of catalyst 


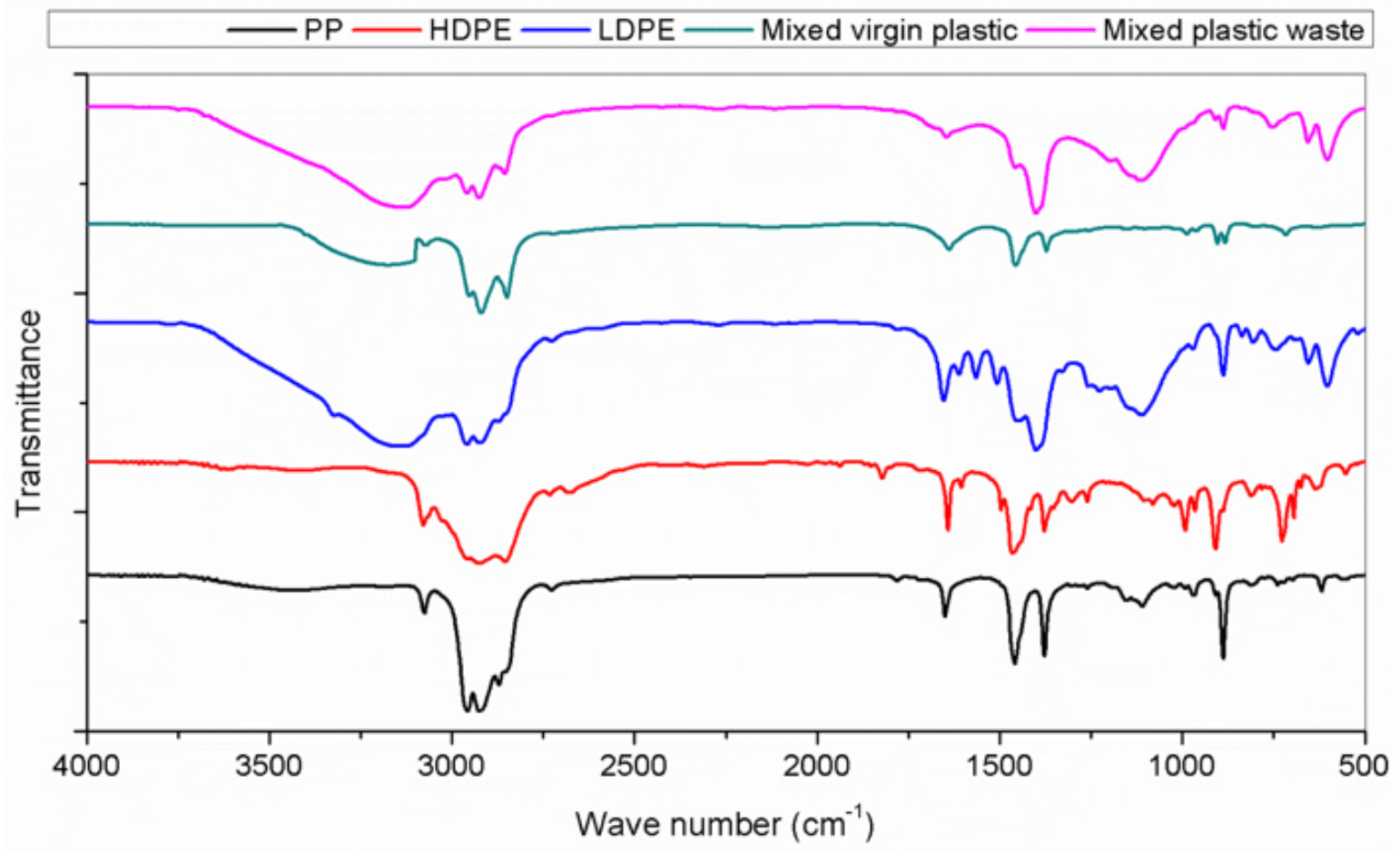

Figure 7

Fourier Transformed Infrared Spectra of liquid hydrocarbon fuel from plastics

\section{Supplementary Files}

This is a list of supplementary files associated with this preprint. Click to download.

- Supplementryfile.docx 